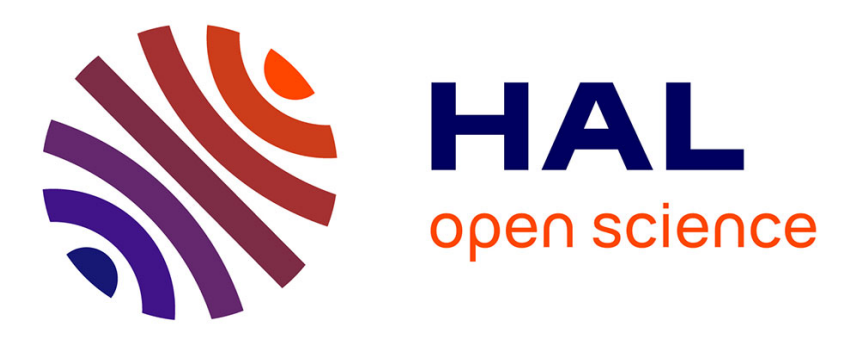

\title{
Correlations between gaseous and liquid phase chemistries induced by cold atmospheric plasmas in a physiological buffer
}

Fanny Girard, Mathieu Peret, Natacha Dumont, Sylvie Blanc, Vasilica Badets, Kristaq Gazeli, Cédric Noël, Thierry Belmonte, Laurent Marlin, Jean-Pierre Cambus, et al.

\section{To cite this version:}

Fanny Girard, Mathieu Peret, Natacha Dumont, Sylvie Blanc, Vasilica Badets, et al.. Correlations between gaseous and liquid phase chemistries induced by cold atmospheric plasmas in a physiological buffer. Physical Chemistry Chemical Physics, 2018, 20 (14), pp.9198 - 9210. 10.1039/C8CP00264A . hal-01781701

\section{HAL Id: hal-01781701 \\ https://hal.science/hal-01781701}

Submitted on 9 Feb 2021

HAL is a multi-disciplinary open access archive for the deposit and dissemination of scientific research documents, whether they are published or not. The documents may come from teaching and research institutions in France or abroad, or from public or private research centers.
L'archive ouverte pluridisciplinaire HAL, est destinée au dépôt et à la diffusion de documents scientifiques de niveau recherche, publiés ou non, émanant des établissements d'enseignement et de recherche français ou étrangers, des laboratoires publics ou privés. 


\section{PCCP}

\section{ARTICLE}

\section{Correlations between gaseous and liquid phase chemistries induced by cold atmospheric plasmas in a physiological buffer}

Received 00th January 20xx, Accepted 00th January 20xx

DOI: $10.1039 / x 0 \times x 00000 x$

www.rsc.org/
Fanny Girard, ${ }^{\mathrm{a}, \mathrm{b}}$ Mathieu Peret, ${ }^{\mathrm{a}}$ Natacha Dumont, ${ }^{\mathrm{a}}$ Vasilica Badets, ${ }^{\mathrm{b}}$ Sylvie Blanc, ${ }^{\mathrm{a}}$ Kristaq Gazeli, ${ }^{\mathrm{a}}$ Cédric Noël, ${ }^{\mathrm{c}}$ Thierry Belmonte, ${ }^{\mathrm{c}}$ Laurent Marlin, ${ }^{\mathrm{d}}$ Jean-Pierre Cambus, ${ }^{\mathrm{e}}$ Guillaume Simon, ${ }^{\mathrm{a}}$ Neso Sojic, ${ }^{b}$ Bernard Held, ${ }^{f}$ Stéphane Arbault, ${ }^{b}+$ and Franck Clément ${ }^{a}+$

The understanding of plasma-liquid interactions is of major importance, not only in physical chemistry, chemical engineering and polymer science, but in biomedicine as well as to better control the biological processes induced on/in biological samples by Cold Atmospheric Plasmas (CAPs). Moreover, plasma-air interactions have to be particularly considered since these CAPs propagate in the ambient air. Herein, we developed a helium-based CAP setup equipped with a shielding-gas device, which allows the control of plasma-air interactions. Thanks to this device, we obtained specific diffuse CAPs, with the ability to propagate along several centimetres in the ambient air at atmospheric pressure. Optical Emission Spectroscopy (OES) measurements were performed on these CAPs during their interaction with a liquid medium (Phosphate-Buffered Saline PBS $10 \mathrm{mM}$, pH 7.4) giving valuable information about the induced chemistry as a function of the shielding gas composition (variable $\mathrm{O}_{2} /\left(\mathrm{O}_{2}+\mathrm{N}_{2}\right)$ ratio). Several excited species were detected including $\mathrm{N}_{2}^{+}($First Negative System, FNS), $\mathrm{N}_{2}$ (Second Positive System, SPS) and $\mathrm{HO}$ radical. The ratios between nitrogen/oxygen excited species strongly depend on the $\mathrm{O}_{2} /\left(\mathrm{O}_{2}+\mathrm{N}_{2}\right)$ ratio. The liquid chemistry developed after CAP treatment was investigated by combining electrochemical and UV-visible absorption spectroscopy methods. We detected and quantified stable oxygen and nitrogen species $\left(\mathrm{H}_{2} \mathrm{O}_{2}, \mathrm{NO}_{2}{ }^{-}, \mathrm{NO}_{3}{ }^{-}\right)$along with Reactive Nitrogen Species (RNS) such as the peroxynitrite anion ONOO'. It appears that the RNS/ROS (Reactive Oxygen Species) ratio in the treated liquid depends also on the shielding gas composition. Eventually, the composition of the surrounding environment of CAPs seems to be crucial for the induced plasma chemistry and consequently, for the liquid chemistry. All these results demonstrate clearly that for physical, chemical and biomedical applications, which are usually achieved in ambient air environments, it is necessary to realize an effective control of plasma-air interactions.

\footnotetext{
a. UPPA, IPREM, CNRS UMR 5254, 2 avenue Président Angot, 64000 Pau, France.

b. Univ. BORDEAUX, ISM, CNRS UMR 5255, NSysA group, ENSCBP, 16 avenue Pey Berland, 33607 Pessac, France

c. Univ. Lorraine, CNRS UMR 7198, Institut Jean Lamour, Site Artem, CS 50840,

54011 Nancy Cedex, France

d. UPPA, Atelier de Physique, avenue de l'université, BP1155, 64013 Pau cedex, France

e. Univ. Paul Sabatier, Hopital Rangueil, Laboratoire Hématologie, Bât L2, 1 Avenue du Professeur Jean Poulhès, TSA 50032, 31059 Toulouse Cedex 9, France

f. This author is a retired professor from university Pau \& Pays de L'Adour

† To whom correspondence should be addressed: Dr Franck CLEMENT, email: franck.clement@univ-pau.fr, Tel.: +33 5594076 57; Dr Stéphane ARBAULT, email: stephane.arbault@u-bordeaux.fr, Tel.: +33540008939.
} 


\section{INTRODUCTION}

Plasma-liquid interactions have gained particular attention, not only in physical chemistry, chemical engineering and polymer science, but also in biological and medical applications ${ }^{1-7}$. In the latter case there is a strong need to understand and explain how Cold Atmospheric Plasmas (CAPs) interact with biological samples ${ }^{8-14}$. Usually, CAPs consist of streamer-like guided ionization waves, which are produced at atmospheric pressure and room temperature by means of Dielectric Barrier Discharge (DBD) reactors ${ }^{15}$. The latter are driven with sinusoidal ${ }^{16,18}$ or pulsed high voltages ${ }^{18-21}$ and the generated CAPs interact with the gaseous medium (usually helium or argon), which confines their electromagnetic propagation.

Depending on the experimental conditions chosen, the ionization degree of these partially-ionized gases is found to be in the order of $\left(10^{-6}-10^{-8}\right)^{21-23}$. The produced electromagnetic forces allow the formation of an important chemical reactivity in the gaseous phase and they lead to excitation, dissociation, recombination and other elementary atomic and molecular processes.

Since most of the applications of CAPs are performed in an open-air environment, copious Reactive Oxygen and Nitrogen Species (RONS) ${ }^{8,9}$ are, thus, produced. It has to be noticed that this situation changes critically if the ambient atmosphere conditions (gas type and composition, humidity, temperature, pressure) change during plasma exposures. Consequently, plasma-air interactions have to be carefully scrutinized: species coming from the ambient air (i.e. mainly $\mathrm{N}_{2} / \mathrm{O}_{2}$, but also $\left.\mathrm{H}_{2} \mathrm{O}, \mathrm{CO}_{2}, \ldots\right)$ may interact strongly with the ionization waves modifying, thus, their chemical composition ${ }^{24-26}$. Moreover, it is known that during the treatment of liquid samples with CAPs, evaporation phenomenon occurs ${ }^{27-29}$. Accordingly, water vapour may be introduced in the plasmas, inducing for instance, an increase in $\mathrm{HO}$. radical concentration during the treatment ${ }^{30}$. Consequently, RONS are hypothesized to be produced mainly in the gaseous plasma phase ${ }^{31,32}$.

Additionally, depending on the experimental conditions used, different chemistries can be induced in the liquid medium following complex mechanisms. For biological or biomedical applications, samples are commonly found in liquid form. Plasma-induced chemistry in liquids is known to play a major role in the observed biological effects through the action of manifold RONS ${ }^{5,28,33-35}$. Their production in the liquid phase can vary significantly. Consequently, it is critical to control the gaseous ambient environment of CAPs. Recently, Tresp et $a l^{24}$ presented a shielding gas device with the possibility of adding different percentages of $\mathrm{O}_{2} / \mathrm{N}_{2}$. This device allowed the effective control of the gaseous plasma environment and its chemistry. Thus, the importance of such control process was demonstrated by analysing biological responses and RONS generation induced by CAPs ${ }^{24,36,37}$. Elsewhere, Liu et al. used the same type of process to control the production of RONS and induce myeloma cell apoptosis ${ }^{6}$, while Ito et al., showed that $\mathrm{H}_{2} \mathrm{O}_{2}$ and $\mathrm{NO}_{2}{ }^{-}$concentration in the solution can be tuned by a shielding gas device operating in open air ${ }^{38}$.

In the present study, both chemistries in the plasma and liquid phases were investigated concomitantly. This was achieved by adding to the initial setup reported recently by our group (for details see Girard et al., $2016^{27}$ ) a shielding gas composed of various amounts of $\mathrm{O}_{2} / \mathrm{N}_{2}$, which allowed the control of plasma-air interactions and the better understanding of the complex interplay between ionization waves and liquids. Optical Emission Spectroscopy (OES) measurements were then performed in the close vicinity of the liquid surface, which allowed the identification of excited species in the gas phase as a function of the shielding gas composition. Then, we focused on the detection and quantification of RONS generated in a physiological buffer (Phosphate Buffered Saline PBS, $10 \mathrm{mM}, \mathrm{pH}$ 7.4) including $\mathrm{H}_{2} \mathrm{O}_{2}, \mathrm{NO}_{2}^{-}, \mathrm{NO}_{3}^{-}$and the highly reactive peroxynitrite $\mathrm{ONOO}^{-}$. To achieve this, we combined UV-visible absorption spectroscopy and electrochemistry as complementary methods. Other physico-chemical parameters such as $\mathrm{pH}$ and evaporation process were also investigated. Particular attention was paid for the analysis of the involved chemical mechanisms. Hypotheses and experimental proofs related to the presence of short-lived RONS are suggested and correlations between gaseous and liquid chemistries are thus highlighted.

\section{MATERIAL AND METHODS EXPERIMENTAL SETUP TO GENERATE CAPS}

Figure 1 depicts a schematic representation of the experimental setup used herein. A tungsten filament (100 $\mu \mathrm{m}$ in diameter) is connected to the high voltage source and it is inserted within a first thin quartz tube (inner and outer diameters of 1.14 and $2.5 \mathrm{~mm}$, respectively). This first tube is fed with high purity helium gas (Linde, 99.9995\%) at a constant flow rate (during all the experiments) of $1.67 \mathrm{slm}$ (standard litres per minute). A grounded cylindrical electrode (10mm in length) is placed around the first quartz tube, allowing the formation of wide spreading radial DBDs between the HV filament and the grounded cylindrical electrode. 


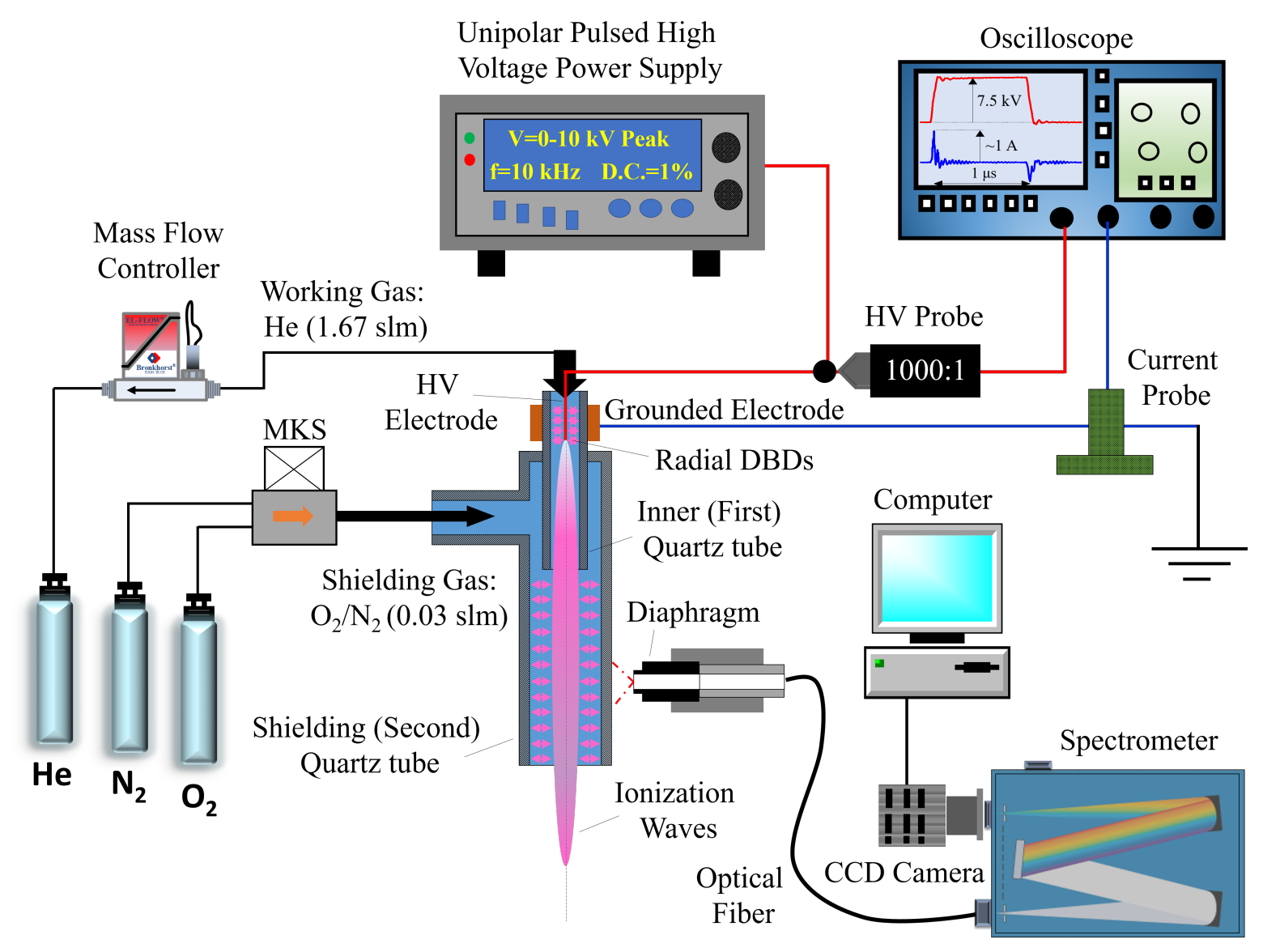

Figure 1. Experimental setup used for the generation of CAPs incorporating a shielding gas device and their analysis via Optical Emission Spectroscopy (OES). Parameters of the unipolar pulsed applied voltage: amplitude $7.5 \mathrm{kV}$, frequency $10 \mathrm{kHz}$, duty cycle $1 \%$. The flow rate is fixed at $1.67 \mathrm{slm}$ for the working gas (flowing in the thin inner quartz tube), and at $0.03 \mathrm{slm}$ for the shielding gas (constant whatever the composition in $\mathrm{O}_{2} / \mathrm{N}_{2}$ is). A detailed cross in the center of the image.

The plasma setup employed for the experiments in this work has been described previously ${ }^{27}$. The control of the gaseous environment around it is achieved using a (second) larger quartz tube, which is placed around the first (thinner) quartz tube (i.e., where the CAP is generated). This configuration allows the addition of a shielding gas device (see Figure 1), which can be compared with other systems reported in the literature ${ }^{24,26,36-38}$.

The advantage of this system is related with the lower gas consumption than other setups 39,40 . Technically, the present shielding gas device is based on the second quartz capillary tube (length: $90 \mathrm{~mm}$, inner and outer diameters: 5.2 and $8 \mathrm{~mm}$, respectively), into which mixtures of $\mathrm{O}_{2}$ and $\mathrm{N}_{2}$ can be added upstream from the nozzle of the inner (first) quartz tube. This way, hydrodynamic interactions with the ionization waves produced in

the working helium gas are better controlled. The shielding gas was composed of $0.03 \mathrm{slm}$ of various $\mathrm{O}_{2} / \mathrm{N}_{2}$ compositions (Linde, $99.9995 \%$ ), which leads to a total gas flow of $1.7 \mathrm{slm}$. The helium flow rate was adjusted with adequate mass flow controllers (EL-FLOW, Bronkhorst High-Tech) connected to a flow-bus. $\mathrm{O}_{2} / \mathrm{N}_{2}$ mixtures were always introduced around the helium gas and they were adjusted using another mass flow controller (MKS in Figure 1).

The production of ionization waves was achieved using a commercial pulsed High Voltage power supply with rise and fall times of pulses in the order of 100 ns. The electrical parameters are fixed as indicated in Figure 1 (i.e. positive pulses of $7.5 \mathrm{kV}$ in amplitude, $10 \mathrm{kHz}$ repetition frequency and $1 \%$ duty cycle (i.e., the ratio of the HV pulse width over the voltage period)). The ionization waves are produced due to the high imposed electric field and the geometric configurations of the extremely thin high voltage electrode and the thin dielectric quartz tube around it, which acts as a guide for the electromagnetic wave propagation.

\section{OPTICAL EMISSION SPECTROSCOPY}

Wavelength-resolved optical characterization has been conducted in order to investigate the chemical composition of the generated CAPs. The plasma 
emission was recorded downstream of the shielding (second) quartz tube (spatially-integrated emission over $2 \mathrm{~mm}$ ) with a wideband optical fibre (Ceramoptec UV 1500/1590 N) equipped with an adequate diaphragm. The diaphragm was placed perpendicularly to the tube axis at a distance $a=5$ $\mathrm{mm}$ from it and at an axial distance $b=38 \mathrm{~mm}$ from the inner (first) tube nozzle. This position corresponds to an optical analysis realized $24 \mathrm{~mm}$ above the surface of the PBS as indicated in Figure 2. Note that for technical reasons, it was not possible to reduce this length. The wavelength-integrated light was then probed by UV-NIR (200-900 $\mathrm{nm}$ ) Optical Emission Spectroscopy (OES) by focusing it on the grating of a high-resolution spectrometer (1000M JOBIN YVON, 1200 groves. $\mathrm{mm}^{-1}$, maximum spectral efficiency at $500 \mathrm{~nm}$ ) equipped with a CCD 3000V light detector (see Figures 1 and 2). All measurements were carried out in triplicate by realizing three independent experiments. Values are calculated as mean \pm Standard Deviation.

The impact of the shielding gas on the induced chemistry was evaluated by analysing the CAPs at various shielding gas compositions. In order to define direct links between excited species detected in the plasma and the reactive oxygen and nitrogen species (RONS) detected in the liquid, OES measurements were performed during the treatment of a buffered liquid (Phosphate Buffer Saline - PBS, $10 \mathrm{mM}, \mathrm{pH}$ 7.4). For that, $2 \mathrm{~mL}$ of PBS solutions were disposed in an adapted well plate and they were exposed to the ionisation waves. A lidding cap was placed over the well for a better control of the gaseous CAP environment and for limiting air-plasma interactions (see Figure 2). To be noted that the lidding cap allows the evacuation of the gas, thanks to a $1 \mathrm{~mm}$ diameter hole, which was drilled on it.

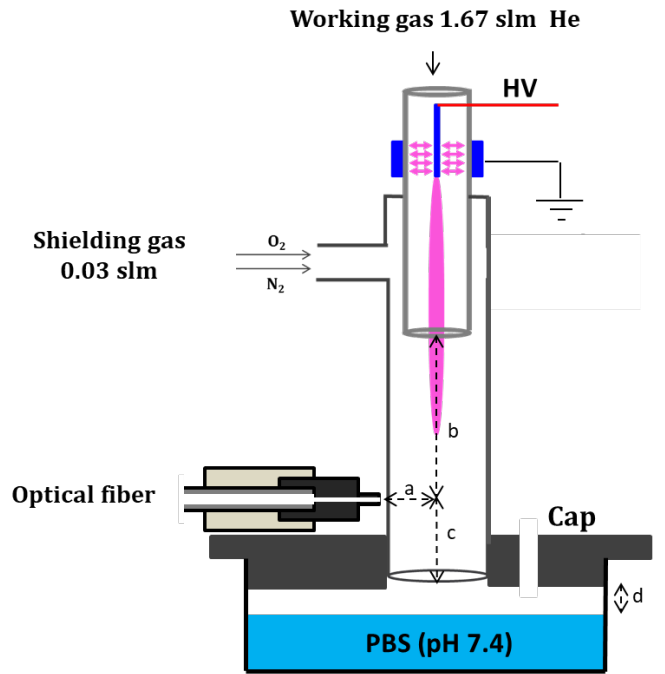

Figure 2. Experimental setup used for optical analyses of the ionisation waves during PBS treatment. $2 \mathrm{~mL}$ of PBS $(10 \mathrm{mM}$, $\mathrm{pH}$ characteristic distances indicated in the scheme are: $\mathrm{a}=5 \mathrm{~mm}, \mathrm{~b}=$ $38 \mathrm{~mm}, \mathrm{c}=22 \mathrm{~mm}$ and $\mathrm{d}=2 \mathrm{~mm}$.

\section{PLASMA TREATMENT OF PHYSIOLOGICAL SOLUTIONS AND PH MEASUREMENTS}

$2 \mathrm{~mL}$ of PBS solutions (10 mM, pH 7.4, PAN BIOTECH, $\mathrm{KCl} 0.003 \mathrm{~mol} . \mathrm{L}^{-1} ; \mathrm{KH}_{2} \mathrm{PO}_{4} 0.002 \mathrm{~mol}^{-1} \mathrm{~L}^{-1} \mathrm{NaCl} 0.137$ mol. $\mathrm{L}^{-1} ; \mathrm{Na}_{2} \mathrm{HPO}_{4} 0.01 \mathrm{~mol} . \mathrm{L}^{-1}$, without $\mathrm{Mg}^{2+} / \mathrm{Ca}^{2+}$ ) were treated in a 6-well plate (FALCON, sterile tissue culture plate), for various shielding gas compositions and during 10 minutes. The distance between the exit of the second quartz tube (i.e., the one corresponding to the shielding device) and the liquid surface was fixed at $d=2 \mathrm{~mm}$ (see Figure 2). For peroxynitrite anion quantification, $2 \mathrm{~mL}$ of PBS solutions at $\mathrm{pH} 12$ were treated by CAPs for each shielding gas composition and they were analysed by UV absorption spectroscopy, as described elsewhere ${ }^{27}$.

$\mathrm{pH}$ measurements were carried out immediately after plasma exposure with a $\mathrm{pH}$ meter (Eutech instruments, $\mathrm{pH} 700$ meter) under magnetic stirring, and after transferring the samples into a haemolysis tube. All measurements were carried out in triplicate by realizing three independent experiments. Values are calculated as mean \pm Standard Deviation. It can be noticed here that $\mathrm{pH}$ variations were measured despite the buffering effect of PBS solutions.

\section{UV-VISIBLE ABSORPTION SPECTROSCOPY}

UV-visible absorption spectroscopy was applied to detect stable nitrogen species and RNS in the PBS exposed to CAPs. The spectra were recorded (Cary 5000 spectrophotometer) at room temperature in the $[200-500 \mathrm{~nm}]$ range $(0.5 \mathrm{~nm}$ steps) using either a $1 \mathrm{~cm}$ - or a $5 \mathrm{~cm}$-path length quartz optical cell (Hellma). The cell length has been chosen adequately in order to reach a maximal absorbance of the analysed solution. Beer-Lambert law was used to calculate the concentration of detected species (Eq. 1):

$A_{\lambda}=\sum_{i} A_{\lambda, i}=\sum_{i} \varepsilon_{\lambda, i} l C_{i}$

$A_{\lambda}$ stands for the total absorbance of the solution at the wavelength $\lambda, A_{\lambda, i}$ the individual absorbance of a species $\mathrm{i}$ at the wavelength $\lambda, \varepsilon_{\lambda, i}$ the molar extinction coefficient of the absorbing species $i$ ${ }^{1} . \mathrm{cm}^{-1}$ ) at the wavelength $\lambda$, / the cell length $(\mathrm{cm})$ and $C_{i}$ the concentration of the absorbing species $i(\mathrm{M})$. The molar extinction coefficients of the species in PBS were taken from the literature ${ }^{41,42}$ or measured directly; standard solutions of nitrite and nitrate ions $\left(\begin{array}{lll}\mathrm{NaNO}_{2} & 2 & \mathrm{mM}\end{array}\right.$ and $\left.\mathrm{NaNO}_{3} 1 \mathrm{mM}\right)$ were thus prepared in PBS pH 7.4, and the absorbance of these species was calculated using the Beer-Lambert law 
for each wavelength (Eq. 1). The molar extinction coefficients were measured also at $\mathrm{pH} 12$ for $\mathrm{ONOO}^{-}$, $\mathrm{HO}_{2}{ }^{-}$and $\mathrm{NO}_{2}{ }^{-}$in order to quantify these species at alkaline values. All measurements were carried out in triplicate by realizing three independent experiments. Values are calculated as mean \pm Standard Deviation.

\section{ELECTROCHEMISTRY}

Electrochemistry was used as a complementary method to UV-visible absorption spectroscopy, in order to detect and quantify RONS, which are different than the previous ones. We performed cyclic voltammetry using a three-electrode electrochemical cell composed of a platinized platinum microelectrode ( $\varnothing 25 \mu \mathrm{m}$ ) as working electrode, an $\mathrm{Ag}$ wire covered by $\mathrm{AgCl}$ as reference electrode and a Pt wire as counter electrode. In order to increase the sensitivity of the working microelectrode, a potentiostatic electro-deposition of platinum black was performed by reducing at -60 $\mathrm{mV}$ versus $\mathrm{Ag} / \mathrm{AgCl} / \mathrm{NaCl} 3 \mathrm{M}$ on the $\mathrm{Pt}$ microelectrode surface, a solution of hydrogen hexachloroplatinate in PBS at pH $7.4\left(\mathrm{H}_{2} \mathrm{PtCl}_{6}, 115\right.$ $\mathrm{mM}$ (Sigma Aldrich )) added with $0.76 \mathrm{mM}$ of lead acetate (Sigma Aldrich) ${ }^{63}$. The electrodeposition was stopped when the total reduction charge reached 0,1 $\mu \mathrm{C} . \mu \mathrm{m}^{-2}$. Indeed, Ben Amor et al., showed that this charge value offers very good analytical performances for the detection of some RONS ${ }^{44}$. The electrochemical measurements were carried out using a potentiostat (BioLogic inc, VSP300, EC-Lab software).

In order to detect RONS in plasma-treated solutions, cyclic voltammograms were achieved between $0 \mathrm{~V}$ and $0.9 \mathrm{~V}$, at $20 \mathrm{mV} . \mathrm{s}^{-1}$ scan rate ${ }^{45,46}$. Quantification of detected species was obtained by using adequate calibration curves extracted from pure solutions of $\mathrm{H}_{2} \mathrm{O}_{2}$ and $\mathrm{NaNO}_{2}$ prepared in PBS buffer (Sigma Aldrich ${ }^{\circ}$.

All measurements were carried out in triplicate by realizing three independent experiments. Values are calculated as mean \pm Standard Deviation.

\section{RESULTS AND DISCUSSION}

\section{MACROSCOPIC OBSERVATIONS OF “DIFFUSE" CAPS}

The use of the (second) shielding quartz tube provides multiple interests, i.e. for the control of the gaseous environment, for consumptions of gases at low total flow rates, but also because it induces the formation of a new type of CAPs. Indeed, with this configuration, a thin very luminous axial plasma is produced and propagates inside the shielding quartz tube, which can be viewed in Figure 3. Additionally, fainter luminous plasmas were observed, which filled entirely the second tube. It seems that this configuration allows the formation of "diffuse" and cylindrical CAPs of about $5 \mathrm{~mm}$ in diameter (inner diameter of the second tube) and $60 \mathrm{~mm}$ in length. Even if the radius of these "diffuse" CAPs decreases once they interact with the atmospheric air, it is remarkable that these plasmas appear relatively stable in the tube and propagate along several centimetres in air, which appears surprising at atmospheric pressure. This behaviour was observed both during the presence and the absence of the shielding at different compositions (see Figure 3).

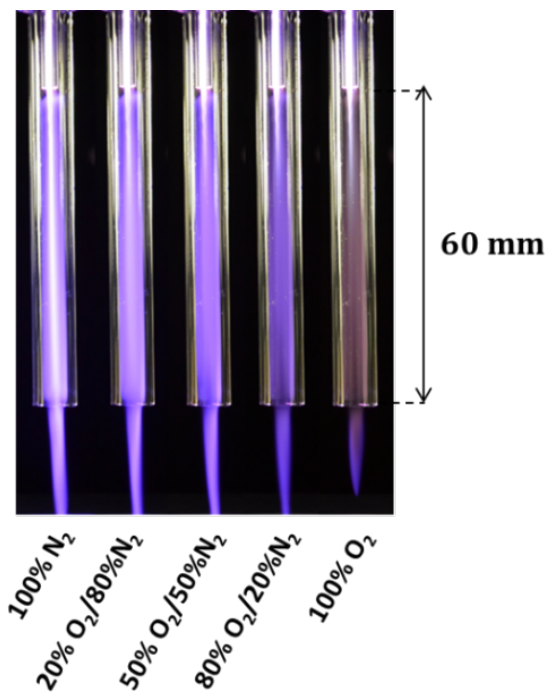

Figure 3. Specific "diffuse" ionization waves generated with the shielding gas device for various $\mathrm{O}_{2} / \mathrm{N}_{2}$ mixtures. The flow rate is fixed at $1.67 \mathrm{slm}$ for the working gas (pure $\mathrm{He}$ ) and at $0.03 \mathrm{slm}$ for the various $\mathrm{O}_{2} / \mathrm{N}_{2}$ compositions added in the surrounding device. CAPs are propagated in air after their exit from the shielding gas tube.

From a physical point of view, it is underlined that these "diffuse" plasmas are true CAPs in nature. Indeed, by analysing via Optical Emission Spectroscopy (OES) the gas phase inside the quartz tube, a dominant emission of the Second Positive System of nitrogen $N_{2}(S P S)$ is measured, suggesting its formation by electronic collisions with molecular nitrogen ${ }^{47}$ (see Figure 4a). Other possible mechanisms leading to $\mathrm{N}_{2}$ (SPS) formation under our experimental conditions could be related with pooling reactions between nitrogen molecule metastable states (i.e., $\left.N_{2}(A)\right)^{48}$. Indeed, as it was shown in our previous work for an unshielded plasma device ${ }^{49}, N_{2}(A)$ is likely to be produced due to the radiative relaxation of the nitrogen molecule first positive system $\left(N_{2}(F P S)\right)$ at various wavelengths in the range $600-900 \mathrm{~nm}$. Besides, the First Negative System of molecular nitrogen ion $\mathrm{N}_{2}^{+}$(FNS) has also been detected, which proves the presence of positive charges (see Figure $4 b$ ). These charged species are crucial for the development of the ionization waves over large distances since, along with the negative ones, they define the localized reduced electric field values. $\mathrm{N}_{2}^{+}$(FNS) could be formed either by electronic collisions with 
ground $\left(N_{2}(X)\right)$ and (mainly) excited state of molecular nitrogen 15,50 . Another important formation pathway is the so-called Penning ionization ${ }^{15,50}$, which is established between helium metastables $\left(\mathrm{He}^{\mathrm{m}}\right)$ and $N_{2}(X)$ giving $N_{2}^{+}(B)$. Then, the $\mathrm{N}_{2}^{+}$(FNS) transition (see Figure $4 \mathrm{~b}$ ) is obtained via radiative relaxation of the $N_{2}^{+}(B)$ to the $N_{2}^{+}(X)$ state. Metastable states, thus, appear to be crucial for such kind of plasmas since they stimulate various reactions in the gaseous chemistry, which in turns will induce modifications on the liquid chemistry.

The colour of the diffuse CAPs depends also on the shielding gas composition. Moreover, the luminous wavelength-integrated intensity of these ionization waves decreases when oxygen is added to the shielding gas (see Figure 3) suggesting the modification of the gaseous chemistry as it was stated above. From a phenomenological point of view, these "diffuse" cold atmospheric plasmas may be explained by the high potential gradient between the axis of the ionization wave (near $7.5 \mathrm{kV}$ potential and highly luminous) and the wall of the shielding quartz tube (near at ground potential). In fact, this system behaves as a multi-streamer discharge generated between a metallic wire and the inner wall of a grounded cylinder.

a)

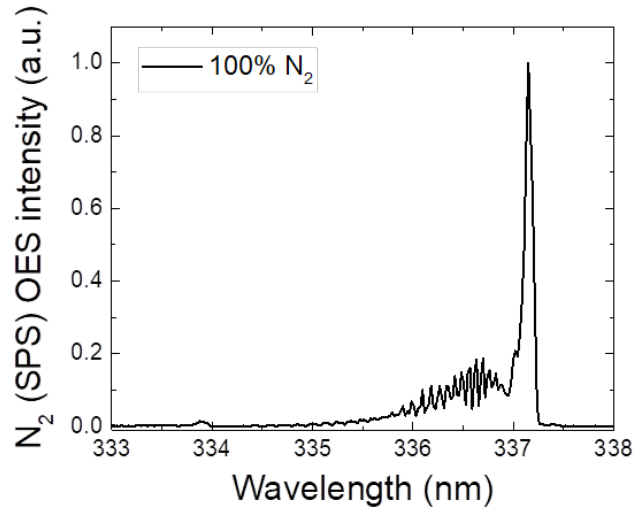

b)

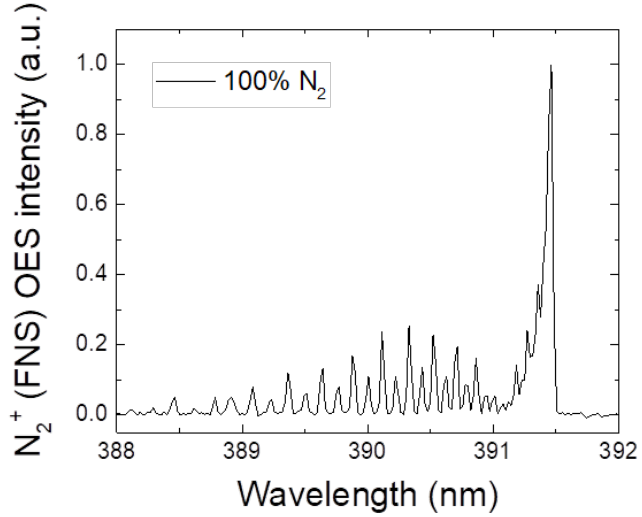

Figure 4. Normalised OES rotational spectra of a) $N_{2}(S P S)$ and b) $N_{2}$ (FNS), measured at $337.1 \mathrm{~nm}$ and $391.4 \mathrm{~nm}$, respectively, in the shielding gas tube for $100 \% \mathrm{~N}_{2}$.

\section{OPTICAL EMISSION SPECTROSCOPY OF CAPS}

The main goal of the present study was to determine the impact of a gaseous environment on the chemistries of the plasma and the exposed liquid. According to our previous study in an open air configuration ${ }^{27}$, the same types of species are expected to be found in this new enclosed configuration, but their ratios could be different depending on the shielding gas composition. In other words, in terms of species nature, one could generalize these results for every CAP system (i.e., with or without shielding device). Although, in terms of species densities, herein it is demonstrated that the present shielding device is advantageous allowing controlled production of well-defined reactive species both in the gaseous and the liquid phase.

Firstly, OES measurements were performed on the plasma phase. Qualitatively, the same species as in our previous works (different reactors ${ }^{49-51}$ and power supplies ${ }^{16}$ were effectively detected: excited $\mathrm{He}, \mathrm{N}_{2}^{+}$(FNS, First Negative System) and $\mathrm{N}_{2}$ (SPS, Second Positive System), which are shown in Figure 4 for the present system, $N_{2}$ (FPS, First Positive System), second order of $\mathrm{NO}^{\circ}, \mathrm{H}_{\alpha}$, second order of $H O$ and $O$. Surprisingly, an additional emission has been detected, corresponding to the first negative band system of $O_{2}^{+}(F N S)\left(b^{4} \Sigma_{\mathrm{g}}^{-} \rightarrow \mathrm{a}^{4} \pi_{\mathrm{u}}\right.$ transition) at $558 \mathrm{~nm}{ }^{52}$, which has not been observed in the unshielded CAPs ${ }^{49}$. OES intensities were then normalized for each species and plotted as function of the shielding gas composition in $\mathrm{O}_{2} / \mathrm{N}_{2}$ (Figure 5). Thus, the intensity for a given specie can only be compared upon the different shielding gas conditions. Figure 5 a depicts He transitions observed at 667.8, 706.5 and $728.1 \mathrm{~nm}$. In Figure 5b and 5c, different excited species coming from nitrogen $\left(N_{2}^{+}\left(\right.\right.$FNS), $N_{2}$ (SPS), $N_{2}$ (FPS) and second order of $\mathrm{NO}^{\circ}$ ) and oxygen derivatives (second order of $\mathrm{HO}$; $\mathrm{O}_{2}^{+}, \mathrm{O}$ and $\mathrm{H}_{\alpha}$ ) are reported, respectively. Note that $\mathrm{O}_{2}{ }^{+}$emission in $100 \% \mathrm{~N}_{2}$ and $20 \% \mathrm{O}_{2} / 80 \% \mathrm{~N}_{2}$ was too weak to be measured and not plotted for these two conditions.

Figure 5 a shows that $\mathrm{He}$ emission intensities reach an optimal value for $20 \% \mathrm{O}_{2} / 80 \% \mathrm{~N}_{2}$ in the shielding gas. On the contrary, the intensity is lower for $100 \%$ $\mathrm{O}_{2}$. In Figure $5 \mathrm{~b}$, we observe that the intensities of the $N_{2}^{+}(F N S)$, the $N_{2}(S P S), N_{2}(F P S)$ and the second order of $\mathrm{NO}^{\circ}$ are higher for $100 \% \mathrm{~N}_{2}$ in the shielding gas. When the $\mathrm{O}_{2} /\left(\mathrm{O}_{2}+\mathrm{N}_{2}\right)$ ratio increases, the UV intensity drops down by about $90 \%$ and cannot even be detected for $100 \% \mathrm{O}_{2}$. For $\mathrm{N}_{2}^{+}$(FNS), $\mathrm{N}_{2}$ (SPS) and $N_{2}(F P S)$, the intensity decreases linearly down to zero when oxygen is added in the shielding gas. Figure $5 \mathrm{c}$ illustrates the intensities of $\mathrm{H}_{\alpha}$ and second order of $\mathrm{HO} ; \mathrm{O}_{2}^{+}$and $\mathrm{O}$ species. When the amount of nitrogen is decreased in the shielding gas, $\mathrm{HO}$ emission decreases exponentially, similarly to $H_{\alpha}$ emission suggesting related creation processes for 
both particles. We can hypothesize a mechanism due to water dissociation. On the other hand, $\mathrm{O}_{2}{ }^{+}$ cation is detected starting from $50 \% \mathrm{O}_{2} / 50 \% \mathrm{~N}_{2}$ in the shielding gas and remains constant for 50,80 and $100 \% \mathrm{O}_{2}$. In turn, atomic oxygen $O$ increases until reaching a maximum plateau value for 80 and $100 \% \mathrm{O}_{2}$.

In a logical way, nitrogen species prevail when the $\mathrm{O}_{2} /\left(\mathrm{O}_{2}+\mathrm{N}_{2}\right)$ ratio is low while on the contrary, oxygen species are predominant for a higher $\mathrm{O}_{2} /\left(\mathrm{O}_{2}+\mathrm{N}_{2}\right)$ ratio. In contrast, $\mathrm{HO}$. radical is mostly detected for $100 \% \mathrm{~N}_{2}$, which is counter intuitive. One mechanism is usually proposed for the formation of $\mathrm{HO}$ (Eq. 2) $1,53,54$ :

$$
\mathrm{N}_{2}\left(\mathrm{~A}^{3} \Sigma_{\mathrm{u}}^{+}\right)+\mathrm{H}_{2} \mathrm{O} \rightarrow \mathrm{HO} \cdot \mathrm{H}^{\cdot}+\mathrm{N}_{2}
$$

Humidity is not controlled in our system but could result from water backscatter of the PBS liquid exposed to the CAPs. The metastable state $N_{2}\left(A^{3} \Sigma_{u}{ }^{+}\right)$ is probably mostly generated by electronic collisions with the fundamental state of $\mathrm{N}_{2}$ molecule, $N_{2}\left(X^{1} \Sigma_{g}^{+}\right)$, and by radiative relaxation of the first excited state of nitrogen $N_{2}\left(B^{3} \Pi_{g}\right)$ to the $N_{2}\left(A^{3} \Sigma_{u}{ }^{+}\right)$ (i.e. $N_{2}$ (FPS) transition, see Eq. 3 below) as it was discussed previously, which is formed by collisions of the fundamental state of $\mathrm{N}_{2}$ molecule, $N_{2}\left(X^{1} \Sigma_{g}^{+}\right)$, with electrons:

$$
N_{2}\left(B^{3} \pi_{g}\right) \rightarrow N_{2}\left(A^{3} \Sigma_{u}^{+}\right)+h v
$$

Considering that $N_{2}$ (FPS) is mostly generated for $100 \% N_{2}$ (Figure 5b), the $N_{2}\left(A^{3} \Sigma_{u}^{+}\right)$metastable state is probably a dominant species for that condition, explaining thus the high yield of $\mathrm{HO}$ - radical.

Finally, the composition $20 \% \mathrm{O}_{2} / 80 \% \mathrm{~N}_{2}$ appears to be critical for the formation/destruction of excited species in the ionization wave. Particularly, $N O^{\circ}$ and $\mathrm{HO}$ - emission intensities decrease strongly when oxygen is added to the shielding gas. Last remark concerns $\mathrm{H}$ atoms, which seem to be more produced for both 100\% $\mathrm{N}_{2}$ and air $\left(\begin{array}{llll}20 \% & \mathrm{O}_{2} / 80 \% & \mathrm{~N}_{2}\end{array}\right)$ conditions but less for higher $\mathrm{O}_{2}$ contents.

This optical study finally shows that the gaseous environment composition of the plasma is a major parameter influencing its chemical reactivity. Besides, three shielding gas compositions appear to be interesting in our experiments:

- $100 \% \mathrm{~N}_{2}$, for which metastable state of nitrogen $N_{2}\left(A^{3} \Sigma_{u}^{+}\right)$appears maximal as well as other nitrogen excited states (SPS, FNS);

- $20 \% \mathrm{O}_{2} / 80 \% \mathrm{~N}_{2}$ (air-equivalent condition), for which an optimal excitation of helium atoms is obtained, but also a modification of $\mathrm{NO}^{\circ}$ and $\mathrm{HO}$ emissions, which decrease drastically, oppositely to an increase of atomic oxygen $\mathrm{O}$ emission;

- $100 \% \mathrm{O}_{2}$, at which all emissions are considerably reduced except those of atomic oxygen $\mathrm{O}$ and dioxygenyl cation $\mathrm{O}_{2}^{+}$.

Consequently, for these three shielding gas compositions, differences in RONS concentrations in the treated liquids are expected. 
a)
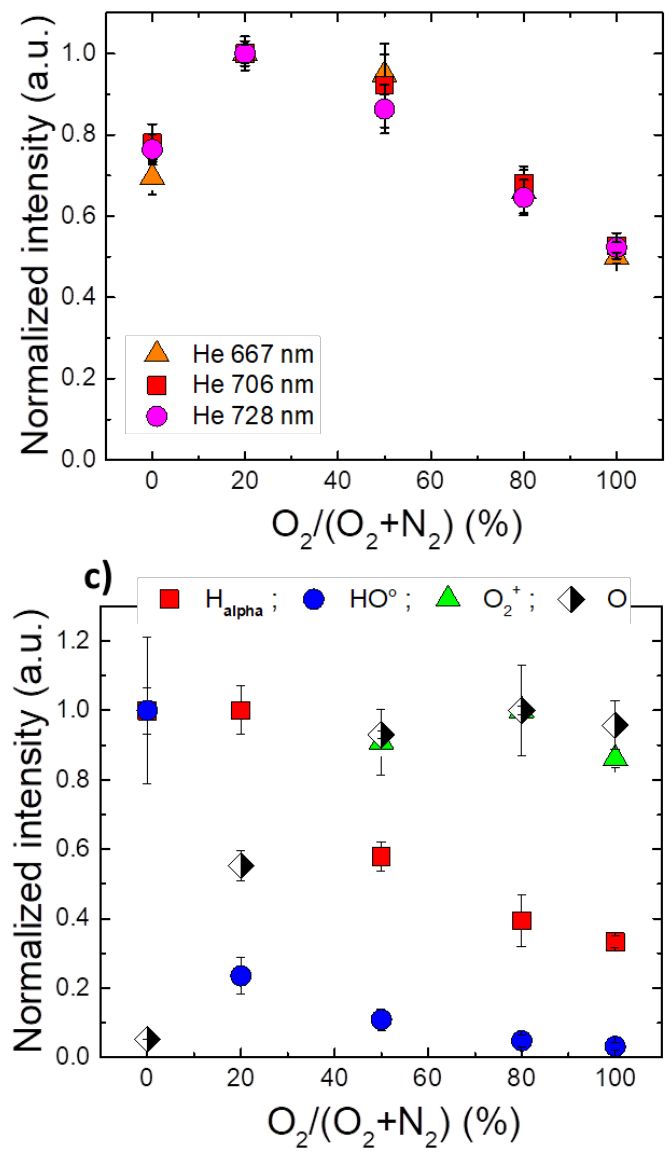

b)

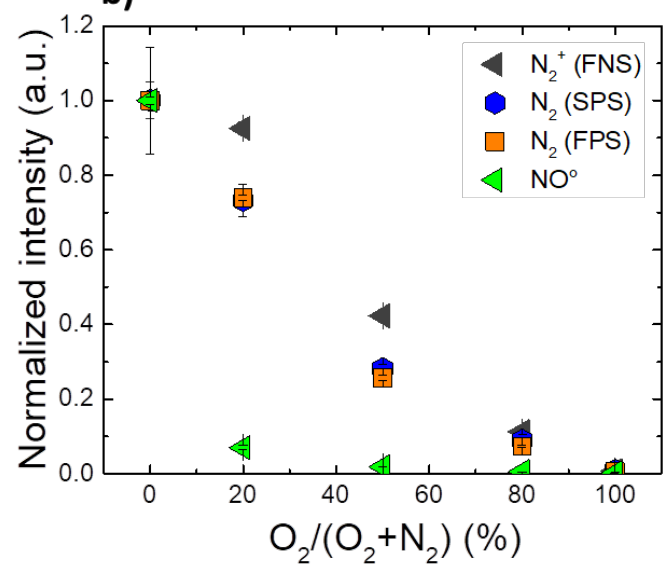

Figure 5. Normalized intensity evolution of a. He at $667.8 \mathrm{~nm}, 706.5$ $\mathrm{nm}$ and $728.1 \mathrm{~nm} ; \mathrm{b} . N_{2}{ }^{+}$FNS at $391.4 \mathrm{~nm}, \mathrm{~N}_{2}$ SPS at $337.1 \mathrm{~nm}, \mathrm{~N}_{2}$ FPS at $762 \mathrm{~nm}$ and second order of $N O^{\circ}$ at $493 \mathrm{~nm} ; c$. $H_{\sigma}$ at $656 \mathrm{~nm}$, second order of $\mathrm{HO}$ at $618 \mathrm{~nm}, \mathrm{O}_{2}{ }^{+}$at $558 \mathrm{~nm}$ and $O$ at $777.5 \mathrm{~nm}$ as a function of the shielding gas composition. All measurements were carried out in triplicate by realizing three independent experiments. Values are calculated as mean \pm SD.

\section{PLASMA TEMPERATURE EVALUATION}

An important parameter of cold atmospheric plasmas is the temperature of the gas, which is crucial for further applications where thermosensible materials are used. In order to estimate the mean temperature of the gas, the traditional analysis of rotational structures of adequate molecular probes has been used in this work, i.e. the transitions of $N_{2}(S P S)\left(C^{3} \Pi_{u} \rightarrow B^{3} \Pi_{g}\right)$ at $337.1 \mathrm{~nm}$, $H O \cdot\left(A^{2} \Sigma^{+} \rightarrow X^{2} \Pi_{i}\right)$ at $309 \quad \mathrm{~nm}$ and $N_{2}^{+}(F N S)\left(B^{2} \Sigma_{u}^{+} \rightarrow X^{2} \Sigma_{g}^{+}\right)$at $391.4 \mathrm{~nm}^{16,49,55-56}$. The rotational temperatures of these molecules were evaluated thanks to the previous OES data presented in Figures 4 and 5 and were plotted as a function of the shielding gas composition in Figure 6.

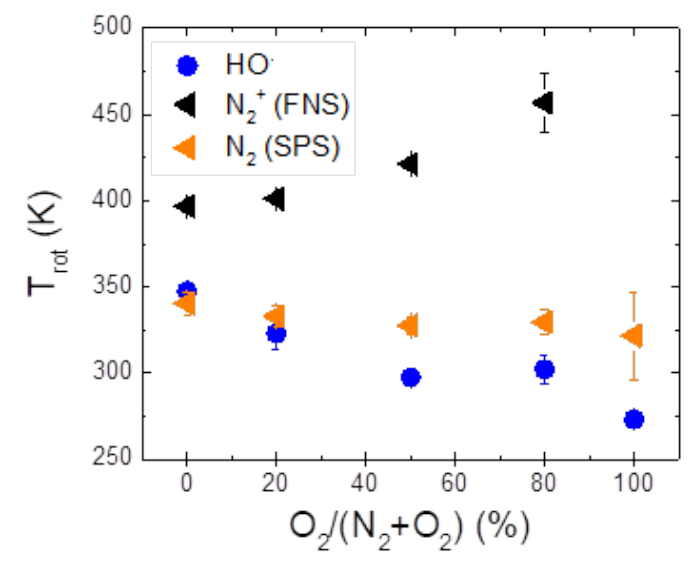

Figure 6. Rotational temperature evolution of the probe molecules $H O \cdot\left(\mathrm{A}^{2} \Sigma^{+} \rightarrow \mathrm{X}^{2} \Pi i\right)$ at $618 \mathrm{~nm}$ (second order), $N_{2}^{+} F N S\left(\mathrm{~B}^{2} \Sigma_{u}^{+} \rightarrow \mathrm{X}^{2} \Sigma_{\mathrm{g}}^{+}\right)$at $391.4 \mathrm{~nm}$ and $N_{2} S P S\left(C^{3} \| u \rightarrow B^{3} \Pi g\right)$ at $337.1 \mathrm{~nm}$ as a function of the $\mathrm{O}_{2} /\left(\mathrm{O}_{2}+\mathrm{N}_{2}\right)$ ratio $(0.03 \mathrm{slm})$. All measurements were carried out in triplicate by realizing three independent experiments. Values are calculated as mean \pm SD.

Results from Figure 6 show that the rotational temperature of $N_{2}^{+}(F N S)$ increases linearly from 400 to $450 \mathrm{~K}$ when oxygen is added in the shielding gas. The last point for $100 \% \mathrm{O}_{2}$ is outlier because the emission band of $N_{2}^{+}(F N S)$ is very weak and not well defined for that condition, so this point has been removed from the Figure 6 . For $\mathrm{N}_{2}(S P S)$ and $\mathrm{HO}$ 
radical, the rotational temperatures are found approximately between 350 and $300 \mathrm{~K}$. Eventually, these rotational temperatures are close to the room temperature, suggesting that the mean temperature of the gas is compatible with thermo-sensitive applications. On the other hand, the rotational temperature of $N_{2}^{+}(F N S)$ is noticeably higher than the ones of $\mathrm{HO}$ and $\mathrm{N}_{2}(S P S)$. This difference is attributed to the generation of helium metastables (justifying furthermore the hypotheses of Figure 4) and helium dimer ions in the guided streamers. Indeed, these molecules contribute effectively to the excitation/ionization of $N_{2}(X)$ at the $N_{2}^{+}(B)$ level due to Penning ionization. In this case, $N_{2}^{+}(B)$ is expected to be excited at high rotational energy levels along with an overpopulation of this excited state. There is thus an absence of equilibrium between this molecular ion's rotational degrees of freedom and the translational ones of the gaseous species (i.e. gas temperature), leading to higher rotational temperatures. Such mechanisms were not found for the other two molecules under our experimental conditions and their rotational temperatures remain close to the room's one. These differences on the rotational temperatures between these molecules are the same with the ones observed for unshielded CAPs devices ${ }^{49}$, which shows that the shielding device doesn't play a role on the temperature of CAPs.

\section{QUANTIFICATION OF EVAPORATION}

A possible evaporation of the solution under exposure to the plasma is a factor necessary to evaluate since it may have a direct impact on the plasma chemistry. This phenomenon has to be quantified for any application of CAPs. In our case, the evaporation cannot be due to a temperature increase, according to rotational temperatures estimated above and the volume of treated solution $(2 \mathrm{~mL})$. The remaining volume was measured for 10 minutes of plasma treatment, for each condition of shielding gas composition. Results are depicted below (Figure 7):

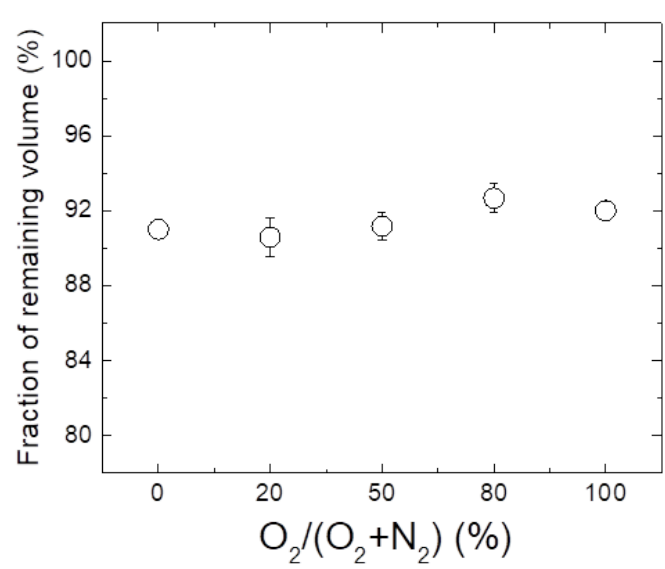

Figure 7. PBS volume evolution ( $\mathrm{pH} 7.4$, room temperature) after 10 minutes of CAP treatment (working gas $1.67 \mathrm{slm} \mathrm{He}$ ) for various shielding gas compositions (0.03 slm). Initial volume: $2 \mathrm{~mL}$. All measurements were carried out in triplicate by realizing three

The evaporation was found to reach about $10 \%$ in all conditions and was twice reduced as compared with the non-shielded setup, for the same treatment time of 10 minutes ${ }^{27}$. Here, the gas flow rate is lower (i.e. 1.7 vs. $2 \mathrm{~s} / \mathrm{m}$ ) so its influence on the liquid is less important. In addition, due to the enclosed environment around the liquid, the water vapour is kept inside the capped well. This result seems to show that, for any condition in the well, the gaseous environment of the ionization wave affects its velocity with an identical hydrodynamic manner, probably due to the presence of a lid over the well. In contrast, it is not the case for the macroscopic aspect of these "diffuse" plasmas (Figure 3), when the ionization wave arrives into the ambient air. Indeed, the CAP with pure oxygen shielding is shorter than the other ones.

Finally, as the evaporation remains constant whichever the conditions are, it can be considered as a non-influencing parameter for the interpretation of the induced chemistry in the liquid investigated below.

\section{MEASUREMENTS OF STABLE NITROGEN SPECIES PRODUCED BY CAPS IN PBS (PH 7.4)}

Electrochemistry and UV-visible absorption spectroscopy have been employed as complementary methods for the identification and quantification of stable oxygen and nitrogen species dissolved in PBS ( $\mathrm{pH}$ 7.4) after plasma treatment (10 min), for several shielding gas compositions.

Figure 8 shows cyclic voltammograms detected on platinized microelectrodes in PBS solutions after various plasma treatments. As shown in a previous report ${ }^{27}$, two distinct oxidation waves appear following the exposure of PBS to our plasmas: the first one corresponds to the irreversible oxidation of 
$\mathrm{H}_{2} \mathrm{O}_{2}$ between 160 and $500 \mathrm{mV}$ and the second one is related to the irreversible oxidation of $\mathrm{NO}_{2}^{-}$ between 650 and $850 \mathrm{mV}$ vs $\mathrm{Ag} / \mathrm{AgCl}$. Moreover, the currents vary as a function of the shielding gas condition; so one can expect different final ratios of $\mathrm{H}_{2} \mathrm{O}_{2} / \mathrm{NO}_{2}{ }^{-}$. Then, we evaluated the concentrations of these species by using calibration curves extracted from pure solutions of $\mathrm{H}_{2} \mathrm{O}_{2}$ and $\mathrm{NaNO}_{2}$ prepared in PBS buffer at $\mathrm{pH}$ 7.4. Based on these calibration curves, the concentrations of each species were obtained at each shielding gas composition and plotted as function of the $\mathrm{O}_{2} /\left(\mathrm{O}_{2}+\mathrm{N}_{2}\right)$ ratio (see Figure 10 )

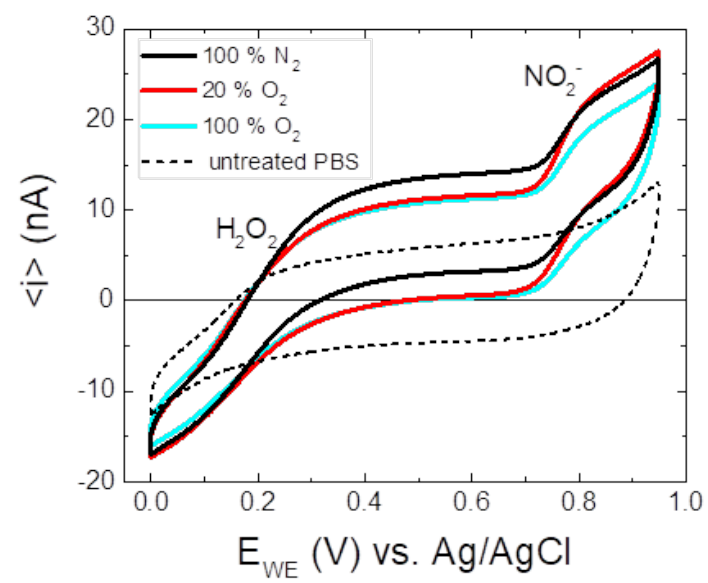

Figure 8. Cyclic voltammograms $\left(20 \mathrm{mV} \cdot \mathrm{s}^{-1}\right)$ measured in $2 \mathrm{~mL}$ of as a function of the shielding gas composition $(0.03 \mathrm{slm})$.

Since Nitrate $\left(\mathrm{NO}_{3}{ }^{-}\right)$ions are not electro-active in our conditions, they were quantified via UV-visible absorption spectroscopy using the Beer-Lambert law at $320 \mathrm{~nm}$ (Eq. 1). Indeed, at this wavelength only $\mathrm{NO}_{2}{ }^{-}$and $\mathrm{NO}_{3}{ }^{-}$are the absorbent species (under 320 $\mathrm{nm}, \mathrm{H}_{2} \mathrm{O}_{2}$ absorbs also). Moreover, nitrite concentrations evaluated by UV absorption spectroscopy were very similar to the ones measured by electrochemistry, showing that these two methods are reliable and complementary to each other (data not shown).

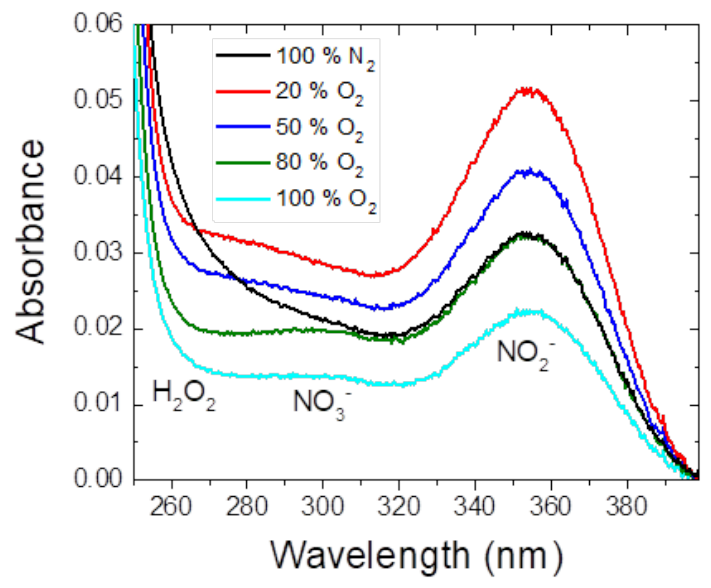

Figure 9. UV absorption spectra (optical length $=5 \mathrm{~cm}$ ) measured in $2 \mathrm{~mL}$ of PBS (pH 7.4) treated 10 minutes by CAP (working gas 1.67 $\mathrm{s} \mathrm{m} \mathrm{He}$ ) as a function of the shielding gas composition (0.03 s/m).

UV spectra in Figure 9 depict 3 contributions: $\mathrm{H}_{2} \mathrm{O}_{2}$ around $260 \mathrm{~nm}$ and nitrate and nitrite peaking at 300 and $354 \mathrm{~nm}$, respectively. The molar extinction coefficients of $\mathrm{NO}_{2}^{-}$and $\mathrm{NO}_{3}^{-}$are respectively $\varepsilon_{\mathrm{NO}_{3}^{-}, 300 \mathrm{~nm}}=8 \mathrm{M}^{-1} \cdot \mathrm{cm}^{-1}, \varepsilon_{\mathrm{NO}}^{-}, 354 \mathrm{~nm}=18,9 \mathrm{M}^{-1} \cdot \mathrm{cm}^{-1}$. They were determined by using standard solutions prepared in PBS and calculated thanks to Eq. 1. In a global manner, the total absorbance of the solution increases when oxygen is added to the shielding gas. For $100 \% \mathrm{~N}_{2}$, the $\mathrm{H}_{2} \mathrm{O}_{2}$ contribution seems to be more important (see black line in Figure 9). This observation is confirmed by cyclic voltammograms (black cycle on Figure 8), because oxidative current corresponding to $\mathrm{H}_{2} \mathrm{O}_{2}$ (plateau current at $300 \mathrm{mV}$ ) is more important for that condition. Following, the concentrations of each species have been calculated thanks to these data and plotted as a function of the $\mathrm{O}_{2} /\left(\mathrm{O}_{2}+\mathrm{N}_{2}\right)$ ratio in the shielding gas. The corresponding results are depicted on Figure 10.

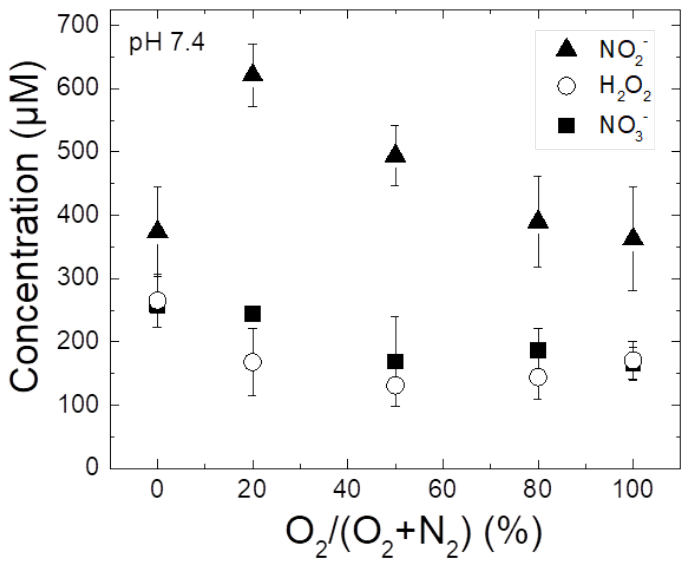

Figure 10. Variations of Nitrite $\left(\mathrm{NO}_{2}{ }^{-}\right)$, hydrogen peroxide $\left(\mathrm{H}_{2} \mathrm{O}_{2}\right)$ and nitrate $\left(\mathrm{NO}_{3}\right)^{-}$concentrations measured in $2 \mathrm{~mL}$ of PBS $(10 \mathrm{mM}, \mathrm{pH}$ v.4) treated 10 minutes by CAPs (working gas $1.67 \mathrm{slm} \mathrm{He}^{2}$ ) for various shielding gas compositions (0.03 $\mathrm{Slm}_{2} . \mathrm{NO}_{2}$ and $\mathrm{H}_{2} \mathrm{O}_{2}$ are visible absorption spectroscopy. All measurements were carried out 

calculated as mean \pm SD.

Globally, the concentrations of $\mathrm{H}_{2} \mathrm{O}_{2}, \mathrm{NO}_{2}{ }^{-}$and $\mathrm{NO}_{3}{ }^{-}$ are in the order of hundreds of micromolar for 10 minutes of CAP treatment. Nitrite ions follow a very clear trend, since a maximum, $620 \pm 50 \mu \mathrm{M}$, is obtained for the condition $20 \% \quad \mathrm{O}_{2} / 80 \% \quad \mathrm{~N}_{2}$. The conditions of $100 \% \quad \mathrm{~N}_{2}, 80 \% \quad \mathrm{O}_{2}$ and $100 \% \mathrm{O}_{2}$ generate roughly the same quantities of $\mathrm{NO}_{2}{ }^{-}: 374 \pm$ $70,390 \pm 70,360 \pm 80 \mu \mathrm{M}$, respectively. Hydrogen peroxide $\left(\mathrm{H}_{2} \mathrm{O}_{2}\right)$, in turn, does not follow the same trend: the concentration is higher for $100 \% \mathrm{~N}_{2}$ in the shielding gas reaching $265 \pm 40 \mu \mathrm{M}$. The trend for nitrate $\mathrm{NO}_{3}{ }^{-}$is similar to the one of $\mathrm{H}_{2} \mathrm{O}_{2}$.

Based on the assessment that nitrite ions are associated with $\mathrm{pH}$ variations ${ }^{27}$, we measured the resulting $\mathrm{pH}$ of $\mathrm{PBS}$ solution after 10 minutes of CAP treatment. For better comparison, concentrations of $\mathrm{NO}_{2}{ }^{-}$were plotted in the same graph (Figure 11).

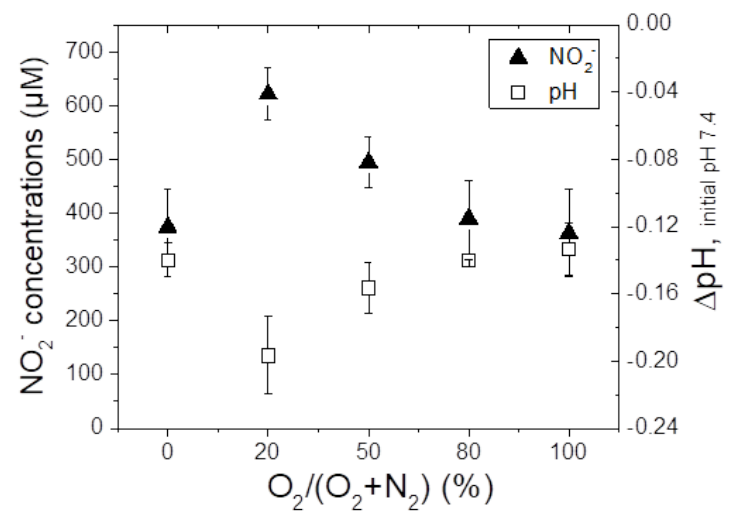

Figure 11. $\mathrm{pH}$ variations measured in $2 \mathrm{~mL}$ of PBS (10 mM, pH 7.4) after a 10 minute treatment by CAP (working gas $1.67 \mathrm{slm}$ He) as a function of the shielding gas composition ( $0.03 \mathrm{slm}$ ). Comparison with $\mathrm{NO}_{2}$ concentrations measured afterwards. All measurements were carried out in triplicate by realizing three independent

For all considered conditions, a pH decrease is observed, $-0.20 \mathrm{pH}$ units at most for the condition of $20 \% \mathrm{O}_{2} / 80 \% \mathrm{~N}_{2}$, which corresponds to "air shielding" and represents an optimum. For $100 \% \mathrm{~N}_{2}$ and $100 \% \mathrm{O}_{2}$, the $\mathrm{pH}$ variations are approximately the same, about $-0.14 \mathrm{pH}$ units. Moreover, these results show a good correlation between $\mathrm{NO}_{2}{ }^{-}$ concentrations and $\mathrm{pH}$ variations. More nitrite are found when $\mathrm{pH}$ lowers. $\mathrm{NO}_{2}{ }^{-}$accumulation could be due to the prior existence of nitrous acid, $\mathrm{HNO}_{2}$. $\mathrm{HNO}_{2}$ is a weak acid $\left(\mathrm{pKa}\left(\left[\mathrm{HNO}_{2} / \mathrm{NO}_{2}{ }^{-}\right]\right)=3.3^{41}\right.$ ) reacting quantitatively with the base of the buffer, $\mathrm{HPO}_{4}{ }^{2-}\left(\mathrm{K}=10^{+3.9}\right)$ leading to $\mathrm{H}_{2} \mathrm{PO}_{4}^{-}$and $\mathrm{NO}_{2}^{-}$. $\mathrm{HNO}_{2}$ can actually be formed in the gaseous phase by the reaction between $\mathrm{HO}$ and $\mathrm{NO}^{\bullet}{ }^{53,57,58}$ (rate coefficient $3.3 \times 10^{-17} \mathrm{~m}^{3} \mathrm{~s}^{-1}{ }^{53}$ ) (Eq. 4):

$\mathrm{HO}+\mathrm{NO}+\mathrm{M} \rightarrow \mathrm{HNO}_{2}+\mathrm{M}$

with $\mathrm{M}$, representing a third collision partner.
Concerning $\mathrm{H}_{2} \mathrm{O}_{2}$, at a glance, the observation of higher concentrations for $100 \% \mathrm{~N}_{2}$ in the shielding gas, is not intuitive. However, regarding the excited species generated in the gas, $\mathrm{HO}$ emission is maximum for a pure nitrogen shielding (Figure $5 \mathrm{c}$ ). $\mathrm{H}_{2} \mathrm{O}_{2}$ could be formed in the discharge due to the following reaction (Eq. 5) ${ }^{53,57,59}$ :

$\mathrm{HO}+\mathrm{HO}+\mathrm{M} \rightarrow \mathrm{H}_{2} \mathrm{O}_{2}$

with $\mathrm{M}$, representing a third collision partner. Consequently, $\mathrm{HO}$ radicals produced in the plasma are expected to form $\mathrm{H}_{2} \mathrm{O}_{2}$ directly in the gas phase 44,50,53 (Rate coefficient: $2.6 \times 10^{-17} \mathrm{~m}^{3} \mathrm{~s}^{-1},{ }^{53}$ ), followed by its solvation into the liquid since the Henry's constant for $\mathrm{H}_{2} \mathrm{O}_{2}$ is high $\left(\tilde{H}=1.92 \times 10^{6}\right.$ at $\left.300 \mathrm{~K}, 10^{5} \mathrm{~Pa},{ }^{58}\right)$, or by solvation of $\mathrm{HO}$ radicals (detected by RPE in plasma treated liquids ${ }^{60}$ ) and their reaction to form $\mathrm{H}_{2} \mathrm{O}_{2}$ in solution. Note that Tresp et al. found similar results in other liquid media (e.g. $\mathrm{NaCl}$, DPBS and RPMI) and for other plasma parameters ${ }^{24}$.

Since the evaporation is the same for all conditions of shielding gas, concentration variations are clearly the result of different chemistries induced by CAP treatment. The air shielding $\left(20 \% \mathrm{O}_{2} / 80 \% \mathrm{~N}_{2}\right)$ seems to be the most efficient for the production of $\mathrm{NO}_{2}{ }^{-}$. Considering the excited species produced in the gas phase, it is clear that the RNS/ROS ratio in the solution depends on the $\mathrm{O}_{2} /\left(\mathrm{O}_{2}+\mathrm{N}_{2}\right)$ percentage. On the contrary, $\mathrm{NO}_{3}{ }^{-}$does not follow the same trend as $\mathrm{NO}_{2}{ }^{-}$. A possible pathway for $\mathrm{NO}_{3}{ }^{-}$formation is (Eq. 6) ${ }^{58,59}$ :

$\mathrm{NO}_{2} \cdot+\mathrm{HO}+\mathrm{M} \rightarrow \mathrm{HNO}_{3}+\mathrm{M}$

with $\mathrm{M}$, representing a third collision partner. $\mathrm{NO}_{2}{ }^{\circ}$ radical is expected to be generated under our conditions since its formation is owed to $N \mathrm{O}^{\circ}$, due to the following reactions (Eq. 7 and 8$)^{25,57,59}$ :

$\mathrm{NO}+\mathrm{O} \rightarrow \mathrm{NO}_{2}^{\cdot}$

$\mathrm{NO}^{\circ}+\mathrm{O}_{3} \rightarrow \mathrm{NO}_{2}{ }^{\circ}+\mathrm{O}_{2}$

However, the very good correlation between $\mathrm{NO}_{2}$ and $\mathrm{pH}$ variations (Figure 11 ) seems to show that $\mathrm{HNO}_{2}$ is mostly responsible for the acidification, excluding a priori another source of $\mathrm{H}^{+}$ions. Besides, $\mathrm{NO}_{3}{ }^{-}$ions are possibly produced thanks to another pathway (peroxynitrite decomposition) or already created in the gas phase as suggested by computational studies ${ }^{12,57}$.

On the other hand, it is surprising that $\mathrm{NO}_{2}{ }^{-}$ concentrations are approximately the same for $100 \% \mathrm{~N}_{2}$ and $100 \% \mathrm{O}_{2}$ shieldings (see Figure 10), compare to the amount of RNS in the plasma for these conditions (see Figure 5). Indeed, the RNS/ROS 
ratios in CAPs are inverted for these two conditions (more RNS for $100 \% \mathrm{~N}_{2}$ and more ROS for $100 \% \mathrm{O}_{2}$ ). Nevertheless, nitrite ions are produced at similar quantities in the PBS. This finding suggests first that the chemical mechanisms producing stable nitrogen species in the liquid phase could be shieldingdependent, with different involved chemistries.

Secondly, the liquid chemistry is maybe strongly dependent on the processes occurring near the plasma-liquid interface, knowing that there is an air layer above the surface. Indeed, when the plasma propagates into the well under the cap, its interaction with the air may influence its own chemistry, independently of former chemical processes that occurred within the tube over several centimetres. Finally, the small amount of nitrogen excited species detected for $100 \% \mathrm{O}_{2}$ in the shielding gas is probably enhanced when the ionization wave is in contact with $\mathrm{N}_{2}$ from air in the well.

\section{MEASUREMENTS OF PEROXYNITRITE: AN UNSTABLE RNS}

The formation of $\mathrm{ONOO}^{-}$in treated PBS was evaluated by UV absorption spectroscopy in alkaline PBS ( $\mathrm{pH} 12)$, in order to stabilise chemically this species. In fact, acid and basic forms of peroxynitrite decompose into nitrite and nitrate in various ratios depending on multiple factors: $\mathrm{pH}$, temperature, concentration, chemical reaction with other species $\left(\mathrm{CO}_{2}\right.$, phosphates) ${ }^{61-64}$. Here, peroxynitrite anion $\mathrm{ONOO}^{-}$has been detected and quantified in $2 \mathrm{~mL}$ of PBS solution $(\mathrm{pH} 12)$ treated by CAP for all conditions of shielding gas. Corresponding UV spectra are depicted in Figure 12.

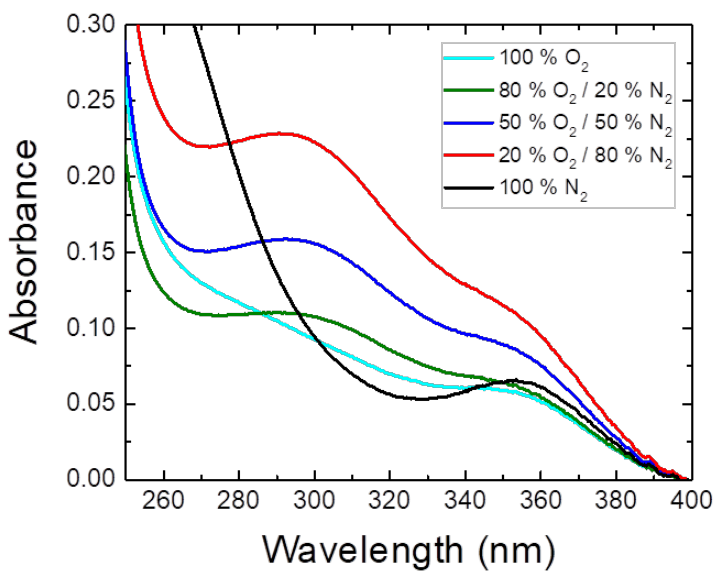

Figure 12: UV spectra $(\mathrm{l}=5 \mathrm{~cm})$ measured in $2 \mathrm{~mL}$ of PBS $(\mathrm{pH} \mathrm{12})$, 列 shielding conditions $(0.03 \mathrm{~s} / \mathrm{m})$.

These spectra reveal the presence of at least 3 species, i.e. $\mathrm{HO}_{2}^{-}$(basic form of $\mathrm{H}_{2} \mathrm{O}_{2}$ ) around 260 $\mathrm{nm}, \mathrm{ONOO}^{-}$at $300 \mathrm{~nm}$ and $\mathrm{NO}_{2}^{-}$at $350 \mathrm{~nm}$. $\mathrm{ONOO}^{-}$ concentrations were calculated using the BeerLambert law, following the method described previously ${ }^{27}$ and plotted as a function of the $\mathrm{O}_{2} /\left(\mathrm{O}_{2}+\mathrm{N}_{2}\right)$ ratio (Figure 13). Firstly, the concentrations are quite low (tens of micromoles) for 10 minutes of treatment. Secondly, the trend is very similar to the one of $\mathrm{NO}_{2}{ }^{-}$. Indeed, the condition $\left(\begin{array}{lll}20 \% & \mathrm{O}_{2} / 80 \% & \mathrm{~N}_{2}\end{array}\right)$ generates once more higher concentrations, about $23 \pm 4 \mu \mathrm{M}$. For $100 \% \mathrm{~N}_{2}$ and $100 \% \mathrm{O}_{2}$ as shielding gas composition, concentrations reach about $10 \mu \mathrm{M}$.

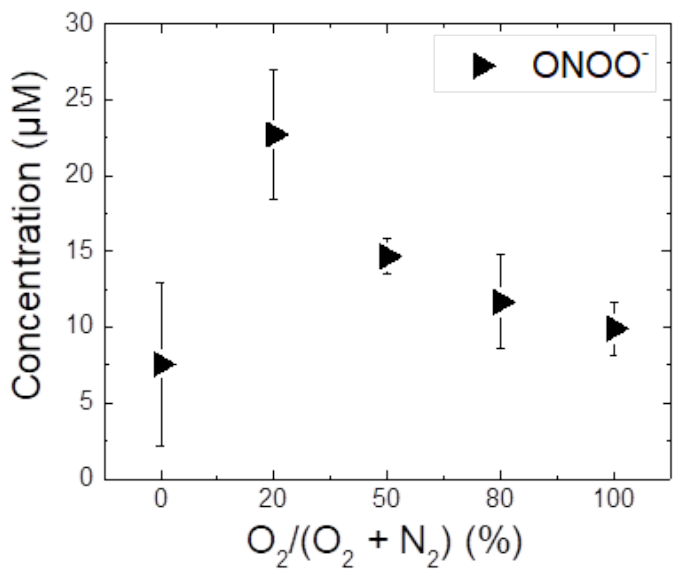

Figure 13. Peroxynitrite (ONOO') concentrations measured by UV absorption spectroscopy in PBS ( $\mathrm{pH} 12)$ treated 10 minutes by CAP (working gas $1.67 \mathrm{slm} \mathrm{He}$ ) for various shielding conditions ( $(0.03$ slm). All measurements were carried out in triplicate by realizing SD.

These results suggest that $\mathrm{ONOO}^{-}$may be one of the precursor of $\mathrm{NO}_{2}{ }^{-}$, or that a common mother species would be involved for the production of both peroxynitrite and nitrite. In addition, since the production of $\mathrm{NO}_{2}^{-}$is very similar at $\mathrm{pH} 7.4$ and 12 (see Figure 14), it may be due mostly to species which acid-base equilibrium does not fall within this range of pHs. It was often hypothesize in literature that $\mathrm{HNO}_{2}$ is a major species produced in airdependent CAPs, which is compatible with the decrease of $\mathrm{pH}$ observed in treated PBS and with the accumulation of $\mathrm{NO}_{2}^{-}$in the solution as function of time. In other words, nitrous acid is probably the major source of nitrite present at substantially high concentrations in exposed physiological buffer. 


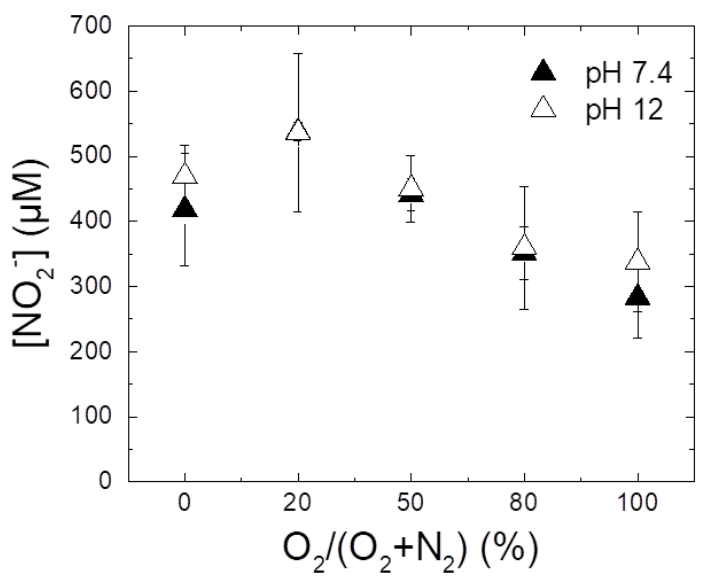

Figure 14. Comparison of nitrite $\left(\mathrm{NO}_{2}{ }^{-}\right)$concentrations measured in PBS at $\mathrm{PH} 7.4$ and 12 for various shielding gas compositions after 10 minutes of CAP treatment. $\mathrm{NO}_{2}$ were measured thanks to UVvisible absorption spectroscopy. All measurements were carried out calculated as mean \pm SD.

\section{CONCLUSION}

In this work, a shielding gas device was used to modulate and study plasma and liquid chemistries, regarding the gaseous environment of the ionization wave. Specific "diffuse" CAPs were obtained, with the characteristic to propagate along several centimetres into the ambient air. The different plasmas were characterized by OES measurements of the luminous area found in a close vicinity of the liquid and covered by the shielding tube, revealing the presence of charges (such as $\mathrm{N}_{2}^{+}(F N S)$ ), and other species originating from electronic collisions with ground state atoms and molecules. This showed that these "diffuse" plasmas have the same characteristics as most of CAPs. Moreover, OES measurements demonstrated the strong influence of the shielding gas composition on the plasma chemistry. In fact, the nitrogen/oxygen excited species ratio in the gas phase depends on the $\mathrm{O}_{2} /\left(\mathrm{O}_{2}+\mathrm{N}_{2}\right)$ percentage. As it could be expected, nitrogen species are dominant for a low $\mathrm{O}_{2} /\left(\mathrm{O}_{2}+\mathrm{N}_{2}\right)$ percentage, while oxygen species are dominant for a higher $\mathrm{O}_{2} /\left(\mathrm{O}_{2}+\mathrm{N}_{2}\right)$ percentage. The physicochemistry of PBS, a standard physiological buffer, was investigated using two complementary techniques (UV-visible absorption spectroscopy and electrochemistry). The operating air-condition (20\% $\mathrm{O}_{2} / 80 \% \mathrm{~N}_{2}$ ) appears to be critical for the formation/destruction of exited species in the gas phase, while in the liquid this composition is optimum for the production of RNS such as $\mathrm{NO}_{2}{ }^{-}$and ONOO- Overall, RONS generation is thus shieldingdependent. In addition, different links between gaseous and liquid species are observed. Especially, the metastable state $N_{2}\left(A^{3} \Sigma_{u}^{+}\right)$is probably a precursor of $\mathrm{H}_{2} \mathrm{O}_{2}$ via the formation of the hydroxyl radical $\mathrm{HO}$. Moreover, hydrogen peroxide $\mathrm{H}_{2} \mathrm{O}_{2}$ is probably already formed in the gas phase, but the possibility that a proportion could be produced in solution cannot be excluded, since $\mathrm{HO}$. radicals are solvated in the liquid. Finally, the chemistry occurring at the plasma-liquid interface seems to be essential for the ionization wave chemistry, as well as the induced-liquid chemistry, proving that the gaseous environment of the plasma is essential and need to be controlled.

\section{ACKNOWLEDGMENTS}

This work was financially supported by the Centre National de la Recherche Scientifique (CNRS), the French Ministry of Research (MESR) and the Agence nationale de la Recherche (ANR, PLASMAREGEN project, no. ANR-14-CE16-0007-01). The current affiliation of K. Gazeli is: LPGP, CNRS, Univ. ParisSud, Université Paris-Saclay, 91405 Orsay, France 


\section{REFERENCES}

1 C. E. Anderson, N. R. Cha, A. D. Lindsay, D. S. Clark and D. B. Graves, The Role of Interfacial Reactions in Determining PlasmaLiquid Chemistry, Plasma Chem. Plasma Process., 2016, 36, 13931415.

2 D. Mariotti, J. Patel, V. Švrček and P. Maguire, Plasma-Liquid Interactions at Atmospheric Pressure for Nanomaterials Synthesis and Surface Engineering, Plasma Process. Polym., 2012, 9, 10741085.

3 P. J. Bruggeman, M. J. Kushner, B. R. Locke, J. G. E. Gardeniers, W. G. Graham, D. B. Graves, R. C. H. M. Hofman-Caris, D. Maric, J. P. Reid, E. Ceriani, D. Fernandez Rivas, J. E. Foster, S. C. Garrick, Y. Gorbanev, S. Hamaguchi, F. Iza, H. Jablonowski, E. Klimova, J. Kolb, F. Krcma, P. Lukes, Z. Machala, I. Marinov, D. Mariotti, S. Mededovic Thagard, D. Minakata, E. C. Neyts, J. Pawlat, Z. L. Petrovic, R. Pflieger, S. Reuter, D. C. Schram, S. Schröter, M. Shiraiwa, B. Tarabová, P. A. Tsai, J. R. R. Verlet, T. von Woedtke, K. R. Wilson, K. Yasui and G. Zvereva, Plasma-liquid interactions: a review and roadmap, Plasma Sources Sci. Technol., 2016, 25, 053002.

$4 \mathrm{H}$. Jablonowski and T. von Woedtke, Research on plasma medicine-relevant plasma-liquid interaction: What happened in the past five years?, Clin. Plasma Med., 2015, 3, 42-52.

5 P. Lukes, E. Dolezalova, I. Sisrova and M. Clupek, Aqueous-phase chemistry and bactericidal effects from an air discharge plasma in contact with water: evidence for the formation of peroxynitrite through a pseudo-second-order post-discharge reaction of $\mathrm{H}_{2} \mathrm{O}_{2}$ and $\mathrm{HNO}_{2}$, Plasma Sources Sci. Technol., 2014, 23, 015019.

6 Z. Liu, D. Xu, D. Liu, Q. Cui, H. Cai, Q. Li, H. Chen and M. G. Kong, Production of simplex RNS and ROS by nanosecond pulse $\mathrm{N}_{2} / \mathrm{O}_{2}$ plasma jets with homogeneous shielding gas for inducing myeloma cell apoptosis, J. Phys. Appl. Phys., 2017, 50, 195204.

7 M. J. Traylor, M. J. Pavlovich, S. Karim, P. Hait, Y. Sakiyama, D. S. Clark and D. B. Graves, Long-term antibacterial efficacy of air plasma-activated water, J. Phys. Appl. Phys., 2011, 44, 472001.

8 D. B. Graves, Low temperature plasma biomedicine: A tutorial review, Phys. Plasmas, 2014, 21, 080901.

9 X. Lu, G. V. Naidis, M. Laroussi, S. Reuter, D. B. Graves and K. Ostrikov, Reactive species in non-equilibrium atmosphericpressure plasmas: Generation, transport, and biological effects, Phys. Rep., 2016, 630, 1-84.

10 M. G. Kong, G. Kroesen, G. Morfill, T. Nosenko, T. Shimizu, J. van Dijk and J. L. Zimmermann, Plasma medicine: an introductory review, New J. Phys., 2009, 11, 115012.

11 S. Maheux, D. Duday, T. Belmonte, C. Penny, H.-M. Cauchie, F. Clément and $\mathrm{P}$. Choquet, Formation of ammonium in saline solution treated by nanosecond pulsed cold atmospheric microplasma: a route to fast inactivation of E. coli bacteria, RSC Adv, 2015, 5, 42135-42140.

12 K. Wende, P. Williams, J. Dalluge, W. V. Gaens, H. Aboubakr, J. Bischof, T. von Woedtke, S. M. Goyal, K.-D. Weltmann, A. Bogaerts,
K. Masur and P. J. Bruggeman, Identification of the biologically active liquid chemistry induced by a nonthermal atmospheric pressure plasma jet, Biointerphases, 2015, 10, 029518.

13 Arben Kojtari, Utku K Ercan, Josh Smith, Gary Friedman, Richard B Sensenig, Somedev Tyagi, Suresh G Joshi, Hai-Feng Ji and Ari D Brooks, Chemistry for Antimicrobial Properties of Water Treated With Non-Equilibrium Plasma, J. Nanomedicine Biotherapeutic Discov., 4: 120, DOI:10.4172/2155-983X.1000120.

14 G. Kamgang-Youbi, J.-M. Herry, T. Meylheuc, J.-L. Brisset, M.-N. Bellon-Fontaine, A. Doubla and M. Naïtali, Microbial inactivation using plasma-activated water obtained by gliding electric discharges, Lett. Appl. Microbiol., 2009, 48, 13-18.

15 X. Lu, G. V. Naidis, M. Laroussi and K. Ostrikov, Guided ionization waves: Theory and experiments, Phys. Rep., 2014, 540, 123-166.

16 K. Gazeli, P. Svarnas, P. Vafeas, P. K. Papadopoulos, A. Gkelios and $\mathrm{F}$. Clément, Investigation on streamers propagating into a helium jet in air at atmospheric pressure: Electrical and optical emission analysis, J. Appl. Phys., 2013, 114, 103304.

17 S. Iseni, A. Schmidt-Bleker, J. Winter, K.-D. Weltmann and S. Reuter, Atmospheric pressure streamer follows the turbulent argon air boundary in a $\mathrm{MHz}$ argon plasma jet investigated by $\mathrm{OH}-$ tracer PLIF spectroscopy, J. Phys. Appl. Phys., 2014, 47, 152001.

18 J. L. Walsh, J. J. Shi and M. G. Kong, Contrasting characteristics of pulsed and sinusoidal cold atmospheric plasma jets, Appl. Phys. Lett., 2006, 88, 171501.

19 B. L. Sands, B. N. Ganguly and K. Tachibana, A streamer-like atmospheric pressure plasma jet, Appl. Phys. Lett., 2008, 92, 151503.

20 Q. Xiong, A. Y. Nikiforov, X. P. Lu and C. Leys, A Branching Streamer Propagation Argon Plasma Plume, IEEE Trans. Plasma Sci., 2011, 39, 2094-2095.

21 J.-P. Boeuf, L. L. Yang and L. C. Pitchford, Dynamics of a guided streamer ("plasma bullet") in a helium jet in air at atmospheric pressure, J. Phys. Appl. Phys., 2013, 46, 015201.

22 G. V. Naidis, Simulation of streamers propagating along helium jets in ambient air: Polarity-induced effects, Appl. Phys. Lett., 2011, 98, 141501.

23 S. Hübner, S. Hofmann, E. M. van Veldhuizen and P. J. Bruggeman, Electron densities and energies of a guided argon streamer in argon and air environments, Plasma Sources Sci. Technol., 2013, 22, 065011.

24 H. Tresp, M. U. Hammer, K.-D. Weltmann and S. Reuter, Effects of atmosphere composition and liquid type on plasma-generated reactive species in biologically relevant solutions, Plasma Med., 2013, 3, 45-55.

25 T. Murakami, K. Niemi, T. Gans, D. O'Connell and W. G. Graham, Chemical kinetics and reactive species in atmospheric pressure helium-oxygen plasmas with humid-air impurities, Plasma Sources Sci. Technol., 2013, 22, 015003.

26 M. Dünnbier, A. Schmidt-Bleker, J. Winter, M. Wolfram, R. Hippler, K.-D. Weltmann and S. Reuter, Ambient air particle transport into the effluent of a cold atmospheric-pressure argon plasma jet investigated by molecular beam mass spectrometry, J. Phys. Appl. Phys., 2013, 46, 435203. 
27 F. Girard, V. Badets, S. Blanc, K. Gazeli, L. Marlin, L. Authier, P. Svarnas, N. Sojic, F. Clément and S. Arbault, Formation of reactive nitrogen species including peroxynitrite in physiological buffer exposed to cold atmospheric plasma, RSC Adv, 2016, 6, 7845778467.

28 S. Ikawa, K. Kitano and S. Hamaguchi, Effects of pH on Bacterial Inactivation in Aqueous Solutions due to Low-Temperature Atmospheric Pressure Plasma Application, Plasma Process. Polym., 2010, 7, 33-42.

29 L. Bundscherer, S. Nagel, S. Hasse, H. Tresp, K. Wende, R. Walther, S. Reuter, K.-D. Weltmann, K. Masur and U. Lindequist, Non-thermal plasma treatment induces MAPK signaling in human monocytes, Open Chem., 2015, 13, 606-613.

30 J. Winter, K. Wende, K. Masur, S. Iseni, M. Dünnbier, M. U. Hammer, H. Tresp, K.-D. Weltmann and S. Reuter, Feed gas humidity: a vital parameter affecting a cold atmospheric-pressure plasma jet and plasma-treated human skin cells, J. Phys. Appl. Phys., 2013, 46, 295401.

31 Y. Gorbanev, D. O'Connell and V. Chechik, Non-Thermal Plasma in Contact with Water: The Origin of Species, Chem. - Eur. J., 2016, 22, 3496-3505.

32 Y. Gorbanev, C. C. W. Verlackt, S. Tinck, E. Tuenter, K. Foubert, P. Cos and A. Bogaerts, Combining experimental and modelling approaches to study the sources of reactive species induced in water by the COST RF plasma jet, Phys. Chem. Chem. Phys., 2018, 2797-2808.

33 M. Vandamme, E. Robert, S. Lerondel, V. Sarron, D. Ries, S. Dozias, J. Sobilo, D. Gosset, C. Kieda, B. Legrain, J.-M. Pouvesle and A. L. Pape, ROS implication in a new antitumor strategy based on non-thermal plasma, Int. J. Cancer, 2012, 130, 2185-2194.

34 H. J. Ahn, K. I. Kim, N. N. Hoan, C. H. Kim, E. Moon, K. S. Choi, S. S. Yang and J.-S. Lee, Targeting Cancer Cells with Reactive Oxygen and Nitrogen Species Generated by Atmospheric-Pressure Air Plasma, PLoS ONE, 2014, 9, e86173.

35 D. B. Graves, The emerging role of reactive oxygen and nitrogen species in redox biology and some implications for plasma applications to medicine and biology, J. Phys. Appl. Phys., 2012, 45, 263001

36 A. Schmidt, S. Bekeschus, H. Jablonowski, A. Barton, K.-D. Weltmann and K. Wende, Role of Ambient Gas Composition on Cold Physical Plasma-Elicited Cell Signaling in Keratinocytes, Biophys. J., 2017, 112, 2397-2407.

37 H. Jablonowski, M. A. C. Hänsch, M. Dünnbier, K. Wende, M. U. Hammer, K.-D. Weltmann, S. Reuter and T. von Woedtke, Plasma jet's shielding gas impact on bacterial inactivation, Biointerphases, 2015, 10, 029506.

38 T. Ito, G. Uchida, A. Nakajima, K. Takenaka and Y. Setsuhara, Control of reactive oxygen and nitrogen species production in liquid by nonthermal plasma jet with controlled surrounding gas, Jpn. J. Appl. Phys., 2017, 56, 01 AC06.

39 A. Schmidt-Bleker, J. Winter, A. Bösel, S. Reuter and K.-D. Weltmann, On the plasma chemistry of a cold atmospheric argon plasma jet with shielding gas device, Plasma Sources Sci. Technol., 2016, 25, 015005.

40 S. Iseni, S. Zhang, A. F. H. van Gessel, S. Hofmann, B. T. J. van Ham, S. Reuter, K.-D. Weltmann and P. J. Bruggeman, Nitric oxide density distributions in the effluent of an RF argon APPJ: effect of gas flow rate and substrate, New J. Phys., 2014, 16, 123011.

41 E. Riordan, N. Minogue, D. Healy, P. O'Driscol and J. R. Sodeau, Spectroscopic and Optimization Modeling Study of Nitrous Acid in Aqueous Solution, J. Phys. Chem. A, 2005, 109, 779-786.

42 D. Vione, M. Minella, V. Maurino and C. Minero, Indirect
Photochemistry in Sunlit Surface Waters: Photoinduced Production of Reactive Transient Species, Chem. - Eur. J., 2014, 20, 10590-10606.

43 S. Ben-Amor, A. Devin, M. Rigoulet, N. Sojic and S. Arbault, Oxygen Plasma Treatment of Platinized Ultramicroelectrodes Increases Sensitivity for Hydrogen Peroxide Detection on Mitochondria, Electroanalysis, 2013, 25, 656-663.

44 S. Ben-Amor, Thesis, Université Bordeaux 1, 2013.

45 C. Amatore, S. Arbault, C. Bouton, K. Coffi, J.-C. Drapier, H. Ghandour and $\mathrm{Y}$. Tong, Monitoring in Real Time with a Microelectrode the Release of Reactive Oxygen and Nitrogen Species by a Single Macrophage Stimulated by its Membrane Mechanical Depolarization, ChemBioChem, 2006, 7, 653-661.

46 S. Ben-Amor, E. Vanhove, F. Sékli Belaïdi, S. Charlot, D. Colin, M. Rigoulet, A. Devin, N. Sojic, J. Launay, P. Temple-Boyer and S. Arbault, Enhanced Detection of Hydrogen Peroxide with Platinized Microelectrode Arrays for Analyses of Mitochondria Activities, Electrochimica Acta, 2014, 126, 171-178.

47 L. Chauvet, Thèse, Université de Toulouse, Université Toulouse III-Paul Sabatier, 2016.

48 Q. Xiong, A. Y. Nikiforov, X. P. Lu and C. Leys, High-speed dispersed photographing of an open-air argon plasma plume by a grating-ICCD camera system, J. Phys. Appl. Phys., 2010, 43, 415201.

49 K. Gazeli, P. Svarnas, B. Held, L. Marlin and F. Clément, Possibility of controlling the chemical pattern of $\mathrm{He}$ and $\mathrm{Ar}$ "guided streamers" by means of $\mathrm{N}_{2}$ or $\mathrm{O}_{2}$ additives, J. Appl. Phys., 2015, 117, 093302.

50 K. Gazeli, C. Noël, F. Clément, C. Daugé, P. Svarnas and T. Belmonte, A study of helium atmospheric-pressure guided streamers for potential biological applications, Plasma Sources Sci. Technol., 2013, 22, 025020.

51 K. Gazeli, L. Doanh, B. Held and F. Clément, Electrical, Thermal and Optical Parametric Study of Guided Ionization Waves Produced with a Compact $\mu$ s-Pulsed DBD-Based Reactor, Plasma, 2017, 1, 3.

52 J. W. McConkey, C. P. Malone, P. V. Johnson, C. Winstead, V. McKoy and I. Kanik, Electron impact dissociation of oxygencontaining molecules-A critical review, Phys. Rep., 2008, 466, 1103.

53 P. Bruggeman and D. C. Schram, On $\mathrm{OH}$ production in water containing atmospheric pressure plasmas, Plasma Sources Sci. Technol., 2010, 19, 045025.

54 S. Kanazawa, H. Kawano, S. Watanabe, T. Furuki, S. Akamine, R. Ichiki, T. Ohkubo, M. Kocik and J. Mizeraczyk, Observation of $\mathrm{OH}$ radicals produced by pulsed discharges on the surface of a liquid, Plasma Sources Sci. Technol., 2011, 20, 034010.

55 P. J. Bruggeman, N. Sadeghi, D. C. Schram and V. Linss, Gas temperature determination from rotational lines in nonequilibrium plasmas: a review, Plasma Sources Sci. Technol., 2014, 23, 023001.

56 R. P. Cardoso, T. Belmonte, P. Keravec, F. Kosior and G. Henrion, Influence of impurities on the temperature of an atmospheric helium plasma in microwave resonant cavity, J. Phys. Appl. Phys., 2007, 40, 1394-1400.

57 Y. Sakiyama, D. B. Graves, H.-W. Chang, T. Shimizu and G. E. Morfill, Plasma chemistry model of surface microdischarge in humid air and dynamics of reactive neutral species, J. Phys. Appl. Phys., 2012, 45, 425201.

$58 \mathrm{~W}$. Tian and M. J. Kushner, Atmospheric pressure dielectric barrier discharges interacting with liquid covered tissue, J. Phys. Appl. Phys., 2014, 47, 165201 
59 Z. Zhang, Z. Xu, C. Cheng, J. Wei, Y. Lan, G. Ni, Q. Sun, S. Qian, H. Zhang, W. Xia, J. Shen, Y. Meng and P. K. Chu, Bactericidal Effects of Plasma Induced Reactive Species in Dielectric Barrier GasLiquid Discharge, Plasma Chem. Plasma Process., 2017, 37, 415431.

60 H. Tresp, M. U. Hammer, J. Winter, K.-D. Weltmann and S. Reuter, Quantitative detection of plasma-generated radicals in liquids by electron paramagnetic resonance spectroscopy, J. Phys. Appl. Phys., 2013, 46, 435401.

61 S. Pfeiffer, A. C. Gorren, K. Schmidt, E. R. Werner, B. Hansert, D. S. Bohle and B. Mayer, Metabolic fate of peroxynitrite in aqueous solution Reaction with nitric oxide and $\mathrm{pH}$-dependent decomposition to nitrite and oxygen in a 2: 1 stoichiometry, J. Biol. Chem., 1997, 272, 3465-3470.

62 C. Molina, R. Kissner and W. H. Koppenol, Decomposition kinetics of peroxynitrite: influence of $\mathrm{pH}$ and buffer, Dalton Trans., 2013, 42, 9898.

63 R. M. Uppu, G. L. Squadrito and W. A. Pryor, Acceleration of peroxynitrite oxidations by carbon dioxide, Arch. Biochem. Biophys., 1996, 327, 335-343.

64 R. Kissner and W. H. Koppenol, Product Distribution of Peroxynitrite Decay as a Function of $\mathrm{pH}$, Temperature, and Concentration, J. Am. Chem. Soc., 2002, 124, 234-239. 